\title{
Las mujeres y la masonería española en el siglo XIX
}

\section{Women and Spanish Freemasonry in the 19th century}

\author{
José Antonio Ferrer Benimeli \\ Universidad de Zaragoza, España \\ bibliotecasalvadorzaragoza@gmail.com
}

Recepción: 15 de agosto de 2018/Aceptación: 20 de septiembre de 2018.

doi: https://doi.org/10.15517/rehmlac.v10i2.35680

Palabras clave

masonería femenina; estudios de género; adopción masónica; España.

Keywords

female freemasonry; gender studies; masonic adoption; Spain.

\section{Resumen}

La relación entre la masonería y las mujeres atrae desde hace varios años las miradas analíticas de la historiografía. Los trabajos se han multiplicado con el objeto de visibilizar la presencia de las mujeres en las logias y dar a conocer las opiniones que los masones expresaron sobre las mujeres como afiliadas y sobre su condición en la sociedad en general. En este artículo se describen los grandes hitos históricos de esta relación y se aclara el paisaje investigativo realizado hasta el momento. La historia de esta relación forma parte de la historia de la masonería y en particular de la española.

\section{Abstract}

The relationship between Freemasonry and women has attracted historiography`s analysis for the past several years. Studies have multiplied in order to make the presence of women in the lodges visible and to communicate the opinions Mason men expressed about women as members and about their condition in society in general. This article describes the great historical milestones of this relationship and clarifies the investigative landscape made so far. The history of this relationship is part of the history of Freemasonry and in particular, that of Spain.

En España, la francmasonería estuvo severamente prohibida y perseguida no solo en el siglo XVIII -a partir de 1738-, sino también en el siglo XIX, hasta 1868. Lo estuvo por la Inquisición y la Iglesia católica por motivos religiosos, y -también- por los reyes y sus gobiernos por motivos políticos. De esta forma, aunque la primera logia reconocida en el continente europeo por la Gran Logia de Londres y Westminster fue la de Madrid en 1728 con el número $50^{1}$, la introducción institucionalizada de la masonería en España con relación al resto de Europa fue muy tardía, ya que hubo que esperar a las libertades constitucionales obtenidas a raíz de la revolución de Cádiz de 1868. Al abrigo de dichas libertades de reunión, expresión y asociación proliferaron por doquier logias y obediencias tanto en la España metropolitana como en la de Ultramar.

\footnotetext{
${ }^{1}$ La de Gibraltar de 1729 lleva el número 51.
} 
El último tercio del siglo XIX español (1870-1900)² es considerado la "edad de oro" de la masonería española, ya que en apenas 30 años se constituyeron más de 1750 logias. Dependientes, eso sí, de múltiples obediencias: Gran Oriente de España, Gran Oriente Nacional de España, Gran Oriente Español, Gran Oriente Lusitano Unido, Gran Logia Simbólica Catalano-Balear, Gran Logia Simbólica del Rito de Memphis y Mizraim, Gran Oriente Ibérico, Gran Logia Unida de España, Gran Logia Independiente, Gran Logia de Andalucía, Confederación Masónica Española, Confederación Masónica de Sevilla, Confederación Masónica Ibero-Americana, Gran Logia Simbólica de la Provincia de Málaga, Gran Oriente Hespérico Reformista, Gran Logia Regional de las Castillas, Gran Logia Regional Galaica, Gran Logia Provincial de Murcia... Sin contar aquellas logias que prefirieron ser independientes o autónomas, o las que optaron por buscar la regularidad masónica en el Supremo Consejo de Francia, en los Grandes Orientes de Francia, Italia y Uruguay o en la Gran Logia Unida de Inglaterra.

Sin embargo, esta masonería tardía en su implantación fue pionera en su preocupación por resolver la cuestión de la iniciación femenina. No hay que olvidar que, si socialmente la situación de la mujer en aquella época era difícil, en la masonería alcanzaba cotas no fáciles de entender. Y más en una institución en la que tenían vetado su ingreso a pesar de definirse como defensora de la dignidad humana, de la solidaridad y fraternidad. Como hace notar Liberté Morte, antigua Gran Maestra de la Gran Logia Femenina de Francia, las logias de adopción aparecieron en España en un momento en el que en Francia la masonería de adopción había casi desaparecido ${ }^{3}$. Otro tanto podríamos decir de Portugal, donde la única logia de adopción de la segunda mitad del siglo XIX -Filipa de Villena-, fundada en diciembre de 1881, se vió obligada a separarse del Grande Oriente Lusitano Unido y a incorporarse en el Grande Oriente de España para poder sobrevivir. Y en Italia la existencia de logias de adopción fue discutida desde 1867 en las diferentes Asambleas Constituyentes del Gran Oriente de Italia hasta que, en la de 1879, se decidió que la masonería italiana no admitía a las mujeres, las cuales debían ser orientadas a la beneficencia y educación ${ }^{4}$.

\footnotetext{
${ }^{2}$ Más exactamente hasta 1896-98, pues con la crisis colonial consecuencia de la guerra con EE. UU. y la independencia de Filipinas (1896) y Puerto Rico y Cuba (1898), la masonería -acusada de ser la causante de dichas pérdidas coloniales- fue perseguida por las autoridades civiles y militares, secuestrados sus archivos y procesados sus grandes maestres. La propia masonería optó por la autodisolución. Hasta 1900, con motivo del Congreso Masónico Internacional de París (31 agosto, 1 y 2 de septiembre), no se reanudará la vida oficial de la masonería española.

${ }^{3}$ Liberté Morte, "La mujer y la masonería", Historia 16, Extra IV: La masonería (noviembre 1977): 21-25.

${ }^{4}$ En Portugal, la única logia de adopción de la segunda mitad del siglo XIX de la que hay datos fue Filipa de Vilhena $n^{\circ}$ 1, filial de la logia Restauraçao de Portugal $n^{\circ} 22$, fundada el 29 de diciembre de 1881 . Poco después, debido a la crisis del Grande Oriente Lusitano Unido - que, según unos, era una Federación de logias y, según otros, una Federación de Ritos-, llegó la expulsión del Gran Oriente de ambas logias, la femenina y la logia madre, y el ingreso en una nueva obediencia denominada Grande Loja dos Maçons Antigos Livres e Aceites de Portugal. En 1884 ambos talleres se separaron de dicha obediencia y se incorporaron en el Grande
} 
Así, pues, a diferencia de otros países con más tradición masónica, la recién creada masonería española no solo dio importancia a logias integradas exclusivamente por mujeres -las llamadas logias de adopción-, sino que en muchas masculinas fueron admitidas mujeres por razones de parentesco en unos casos, o como simple plataforma para su posterior "emancipación". Y lo hicieron con los mismos títulos, rito y derechos que el hombre, mientras en otros países la presencia femenina en la masonería había desaparecido o se encontraba bajo una rigurosa tutela o control. Recordemos que en Francia habrá que esperar a 1945 para que se crease lo que acabaría constituyendo la Gran Logia Femenina de Francia. En tanto que, en España, algunas de las logias de adopción del siglo XIX eran ya verdaderas logias femeninas que no dependían directamente de ninguna masculina, administrándose autónomamente. Sin olvidar que la masonería femenina española es muy anterior a la célebre y polémica iniciación de Maria Deraismes, el 14 de marzo de 1882, en la logia Les Libres-Penseurs de Pec, y a la constitución posterior de la masonería de carácter mixto -el Derecho Humano-, fundada por ella diez años más tarde ${ }^{5}$. Pues en España hay mujeres masonas desde 1871 y logias femeninas de adopción desde 1873. La presencia de masonas en 180 logias masculinas en el último tercio del siglo XIX español es bastante sintomática.

Oriente de España, donde Filipa de Vilhena figura con el número 301 y Restauraçao de Portugal, con el 305. A estas logias se añadieron otras seis -también de Lisboa- que optaron igualmente por el Grande Oriente de España: Confederación $n^{\circ} 301$, Democracia $n^{\circ} 303$, Obreros Unidos $n^{\circ} 304$, Igualdad $n^{\circ} 329$, Libertad $n^{\circ} 330$ y Centro de Paz $n^{\circ} 373$ (Fernando Marques Da Costa, A Maçonaria Feminina (Lisboa: Ed. Vega, 1980), 4850; José Antonio Ferrer Benimeli, "Implantación de logias y distribución geográfico-histórica de la masonería española", en La masonería en la España del siglo XIX (Valladolid: Junta de Castilla y León, 1987), tomo I, 121. En Italia, la masonería oficial de la segunda mitad del siglo XIX, interesada en los problemas de la emancipación, llegó a constituir en 1867 un Comitato Centrale Femminile di Emancipazione en el que tomó parte la naciente masonería de adopción. Pero la emancipación civil de la mujer llevaba necesariamente a la emancipación masónica y a eso se opuso el Gran Oriente de Italia, a pesar del apoyo del Gran Maestre ad vitam Giuseppe Garibaldi, padre espiritual del movimiento femenino del siglo XIX y promotor de la masonería de adopción italiana. La cuestión de las logias de adopción fue abordada en las Asambleas Constituyentes de Nápoles (1867), Florencia (1869 y 1871) y Roma (1872 y 1879). En esta última se acordó que "la masonería italiana no admite logias femeninas, pero se propone el mejoramiento moral, intelectual y económico de la mujer, cuya obra orienta a determinados fines de beneficencia, educación y difusión de los principios masónicos". Más tarde, en el congreso masónico de 1898 - celebrado en Turín-, se añadió que las logias femeninas no habrían acarreado sino perjuicios a la institución y que, dada la condición servil de la mujer, aún no le era posible colaborar con eficacia en la obra masónica (Francesca Vigni. "La masonería femenina italiana entre los siglos XIX y XX". En La masonería española entre Europa y América. Coordinado por. José A. Ferrer Benimeli (Zaragoza: Gobierno de Aragón, 1995), tomo I, 221-230; Vigni e Pier Domenico, Donne e Massoneria in Italia dalle origini ad oggi (Foggia: Bastogi, 1997)).

${ }^{5}$ Gisèle et Yves Hivert-Messeca, Comment la Franc-maçonnerie vint aux femmes. Deux siècles de FrancMaçonnerie d'adoption féminine et mixte en France 1740-1940 (Paris, Dervy, 1997); María José Lacalzada de Mateo, El cimiento mixto en masonería. El Derecho Humano en España 1893-1963) (Madrid: Fundación Maria Deraismes, 2007); Jean-Pierre Bacot, Les filles du pasteur Anderson. Deux siècles de FrancMaçonnerie mixte et féminine en France (Paris: Edimaf, 1988); Karen Bencherit y Carina Louart, La FrancMaçonnerie au feminin (París: Belfond, 1994). 
Al igual que lo es, a pesar de la escasa y dispersa documentación existente de la época, que hayamos podido localizar 732 mujeres masonas ${ }^{6}$, de las que 586 corresponden al período 1870-1898, y 146 al que va de 1900 a 1939, final de la guerra civil e inicio del franquismo que llevó a la persecución y total exterminio de la masonería. Dicho de otra forma, en torno al $80 \%$ de iniciaciones femeninas en España corresponde al último tercio del siglo XIX.

Esta costumbre de iniciar a mujeres en igualdad de condiciones que el hombre fue una práctica bastante generalizada en la masonería española del último tercio del siglo XIX. Las mujeres no solo eran iniciadas en rito masculino, sino que asistían a los trabajos de la logia y adquirían cargos de responsabilidad como vigilantes, orador y secretario.

La presencia femenina en las logias españolas plantea, en primer lugar, un dualismo entre lo "legal" masónico y lo real. Las primeras iniciaciones de mujeres en logias españolas documentadas tienen lugar en 1871, en un momento en el que, en las distintas obediencias españolas, no había directrices claras al respecto, pues las Constituciones de Anderson quedaban muy lejos y ni siquiera habían sido publicadas en España. Por otro lado, al no haber una tradición masónica continuada, como en los demás países, la masonería que se crea en el último tercio del siglo XIX es bastante anárquica, sobre todo si lo comparamos con lo ocurrido en los países más próximos, como Portugal, Francia e Italia.

Pasaron 20 años decisivos hasta que el 30 de marzo de 1891 se publicaron los primeros reglamentos de adopción por el Gran Oriente Nacional de España. Y, un poco después, el 15 de agosto de 1892, por el Gran Oriente Español. Unos y otros fueron promulgados con el objeto de subsanar los problemas de "irregularidad" en los que muchas logias estaban cayendo al iniciar a mujeres bajo el Rito Escocés Antiguo y Aceptado, que fue siempre el de mayor implantación en España?

Las primeras iniciaciones de mujeres en las logias españolas tienen lugar en un contexto especial dada la multiplicidad de obediencias masónicas (cerca de una veintena) y de criterios diferentes a la hora de enfrentarse a las transformaciones sociales que pedían una mayor presencia y protagonismo de la mujer en todos los terrenos. Pero no todos los masones estaban de acuerdo con la iniciación femenina. En algún caso se afirma taxativamente que "la mujer no debe extender su acción más allá del hogar", pues "sus

\footnotetext{
${ }^{6}$ Esta cifra, por supuesto, es muy provisional. En el banco de datos del Centro de Estudios Históricos de la Masonería Española (CEHME), todavía sin concluir, hay 863 registros de masonas, que no es lo mismo que número de masonas, pues 131 figuran en dos o más logias, lo que da un resultado de 732 mujeres iniciadas, a las que conocemos con nombre y apellidos. Quedan excluidas aquellas de las que solo sabemos el nombre simbólico, que son al menos otras 11. Corresponden 586 al siglo XIX. Sin embargo, Françoise Randouyer da la cifra de 580; María José Lacalzada, 547; Suzanne Marza, 537; y Natividad Ortiz Albear, en su Diccionario actualizado, 550. A estas habría que añadir 65 lovetonas.

${ }^{7}$ Boletín Oficial del Grande Oriente Nacional de España [Madrid], no 90 (25 marzo 1891) 1. Boletín Oficial del Gran Oriente Español [Madrid], no 56 (15 agosto 1892) 145. También Ruiz, J. (Alvar Fáñez, Gr. 33), Estatutos y reglamentos generales de la masonería de adopción (Madrid: Impr. Ricardo Rojas, 1892).
} 
deberes de esposa y madre lo exigen así”. Es lo que pensaban algunos masones de la logia Iberia $n^{\circ} 7$ de Madrid a propósito de la educación de la mujer el 24 de marzo de $1890^{8}$.

Un par de años antes, el orador de la logia Patria $n^{\circ} 216$ de Barcelona del Gran Oriente de España se declaraba contrario al hecho de que las mujeres formaran parte de las logias, porque:

[...] no son propias de su temperamento ni de su organismo las discusiones filosóficas, sociales y económicas que... puedan suscitarse... tampoco creo deban enterarse de ciertos incidentes pequeños que por desgracia se promueven en nuestro seno; ante la mujer debemos siempre parecer grandes; ocultemos entre nosotros nuestras miserias ${ }^{9}$.

Sin embargo, en otros casos nos encontramos con actitudes mucho más conciliadoras. Así, por ejemplo, en 1873, el Orador de la logia Estrella Flamígera $n^{\circ}$ 92, de Córdoba, de la misma Obediencia (GODE) en la «tenida de adopción» en la que fue iniciada la hermana Humildad ${ }^{10}$, francesa de nacimiento, entre otras cosas dijo:

Inmenso es el júbilo de que nos hallamos poseídos al abrir por primera vez las puertas de nuestro templo para dar la luz y para que nos ayude en nuestros trabajos esa mitad del género humano, que recibiendo su emancipación con el cristianismo, pudo elevarse de la miserable condición de esclava a la que la vanidad y la tiranía del hombre la había tenido por tantos siglos reducida ${ }^{11}$.

Y después de reconocer que la mujer es el complemento de perfección del hombre ${ }^{12}$, añade:

\footnotetext{
8 “Todos los fanatismos son igualmente reprochables. El de la reacción y el de la libertad [...] Los exagerados en el terreno de las ideas liberales tratan de elevar a la mujer (así lo aseguran) concediéndole iguales pensamientos que al hombre. Quieren que sea sabia, política, literata, que gobierne los pueblos, que forme en los parlamentos, universidades y academias, y por este camino, tan alta quieren ponerla, que de ser realizable tal pensamiento, jno es mala caída la que deparan a ese ser, nacido y creado para constituir el emporio de nuestra gloria [...] La mujer no debe extender su acción más allá del hogar; pero dentro de él no debe ignorar ni aún lo más superfluo. Sus deberes de esposa y madre lo exigen así y hacer lo contrario es negar a la patria ciudadanos aptos para su sostenimiento y defensa [...] Tal es la verdadera misión de la madre...". Citado por Natividad Ortiz Albear, Las mujeres en la masonería (Málaga: Atenea-Universidad, 2005), 18.

${ }^{9}$ La Concordia I, no 4 (noviembre 1888) 31-32. Citado por Pere Sánchez Ferré, La Maçoneria en Catalunya, 1868-1936 (Barcelona: Ed. 62, 1990), 158.

${ }^{10}$ Corresponde a las iniciales M.L. de T.

${ }^{11}$ Boletín Oficial del Grande Oriente de España [Madrid], III, no 57 (1 septiembre 1873) 6-8: "Adopción de la Hermana Humildad en la logia Estrella Flamigera, Oriente de Córdoba.

12 "El hombre sin la mujer o la mujer sin el hombre, no pueden ser reconocidos en la naturaleza como seres perfectos".
} 
Si el hombre por sí solo no es perfecto, ¿cómo habíamos de poder formar una asociación, cuyo principal objeto es llevar a la humanidad por medio de la virtud y la ilustración, al mayor grado de perfección posible si no damos entrada en nuestros templos a la mujer, haciéndola partícipe de nuestros trabajos... ${ }^{13}$.

Años después, en 1883, eran iniciadas en la misma logia Consuelo Delgado de Navas, simbólico Libertad, y la profesora Dolores Navas Delgado, simbólico Astrea ${ }^{14}$.

En esta misma línea se expresará, el 10 de agosto de 1887, Anselmo Lorenzo, Venerable de la logia Hijos del Trabajo, de Barcelona y carismático libertario ${ }^{15}$ :

La logia quiere asociar la mujer a la obra masónica, no para tenerla en estado de adopción y dependencia como si fuese un menor sujeto a permanente tutela, sino para elevarla a la categoría de miembro activo, reconociendo a la iniciada al igual que a los demás hermanos del cuadro los mismos derechos y los mismos deberes ${ }^{16}$.

Y concluía diciendo que la logia Hijos del Trabajo tenía abiertas sus puertas "a la mujer virtuosa, digna y progresiva".

Por su parte la logia Regeneración $n^{\circ} 118$ de Cádiz proponía, también en 1887, promover tenidas blancas y escuelas laicas intentando atraer a la masonería a maestros y maestras de primera enseñanza, "condonándoles si fuera preciso los derechos de iniciación”. Y añadían que la logia:

[...] ávida de ensanchar los límites que las tradiciones marcaban a la masonería no ha titubeado en abrir sus puertas a la mujer; no formando cámaras de adopción... sino ofreciéndola un puesto en su cuadro y haciéndola partícipe de sus trabajos en bien general de la $\operatorname{Orden}^{17}$.

En la fiesta del primer aniversario celebrada por la logia madrileña 5 de abril del 88 , que tuvo lugar lógicamente el 5 de abril de 1889, entre los brindis finales hubo uno muy

\footnotetext{
${ }^{13}$ Citado por Eduardo Enríquez del Árbol, “La masonería española y la mujer en el sexenio democrático (1868-1874)", Anuario de Historia Contemporánea 14 (1987-91): 57.

${ }^{14}$ Francisco Moreno Gómez y Juan Ortiz Villalba, La masonería en Córdoba (Córdoba: Ed. Albolafia, 1985), 233-234. En esta logia de un total de 87 miembros solo hay constancia de las tres iniciadas ya citadas.

15 Una breve biografía suya en Encyclopédie de la Franc-Maçonnerie [dir. Eric Saunier] (Paris: La Pochothèque, 2010), 509-511.

${ }^{16}$ Citado por Sánchez Ferré, "La Maçoneria”, 154; y por Françoise Randouyer: "Presencia femenina precoz en las logias españolas (1868-1898)”, en La masonería española en el 2000. Una revisión histórica, coord. Ferrer Benimeli (Zaragoza: Gobierno de Aragón, 2001), tomo II, 608.

${ }^{17}$ Paz López García, Antonio Morales Benítez y Fernando Sigler Silvera, "La mujer en la masonería gaditana. Estudios de las logias". en La masonería española entre Europa y América, coord. Ferrer Benimeli (Zaragoza Gobierno de Aragón, 1995), tomo I, 204.
} 
significativo, realizado por la hermana Ángeles López de Ayala y dedicado al hermano y Gran Maestre Vizconde de Ros:

[...] que dignificaba a la mujer elevándola al igual del hombre, y reconociéndola los derechos de la personalidad, lo cual hoy es favor y no justicia, por la ignorancia de la mujer en general.

Y añadía:

Se ha dado un gran paso hacia la emancipación de la mujer por los $\mathrm{HH}$. Vizconde de Ros y Moncada, secundados eficazmente por la logia a que pertenezco [Hijas de los Pobres]; la masonería será el redentor de nuestro sexo ${ }^{18}$.

La primera noticia de mujeres masonas en España fue de principios de 1871 en la logia madrileña Comuneros de Castilla, $n^{\circ} 289$, perteneciente al Gran Oriente de España. Se trata de Amalia Antigüedad, simbólico Cesarea, gr. $3^{\circ}$, y de Elvira Chacel, Mariana Pineda, gr. $3^{\text {o19. }}$.

Cronológicamente, la siguiente información corresponde a la iniciación de mujeres en la logia Bética de Málaga y la recoge el Boletín Oficial del Grande Oriente de España en su número del 15 de junio de $1872^{20}$. Unos meses después, en octubre, el mismo Boletín dice que "hacía poco tiempo" que también había sido iniciada una profana en la logia Moralidad de Barcelona. Y en los últimos días -añadía- "habían recibido la luz" en la logia Silencio, de los mismos valles, tres señoras más. Y, a estas iban a seguir otras, que permitirían muy pronto por su número formar una logia de adopción.

De 1872 fueron igualmente las primeras iniciaciones de mujeres en Madrid en las logias Minerva e Hijos del Trabajo. En esta última se propuso crear un organismo femenino llamado Las Hijas del Sol, con el objetivo de "arrancar a la mujer de la dura servidumbre del fanatismo en que vive y [que] llegue a ser instrumento de una verdadera regeneración social"'21. La aspiración de esta nueva institución, según recoge el Boletín

${ }^{18}$ Ferrer Benimeli. Masonería española contemporánea (Madrid: Siglo XXI de España Ed., 1980), tomo I, 19.

${ }^{19}$ Las dos causaron baja en la logia el 1 de mayo de 1871 por falta de asistencia (Ortiz Albear, Las mujeres en la masonería, 95).

${ }^{20}$ Boletín Oficial del Grande Oriente de España, II, no 36 (15 octubre 1872), 12. La noticia concluía así: "Saludamos con fraternal cariño a las masonas iniciadas y esperamos mucho de los especiales trabajos a que habrán de dedicarse para la propagación de nuestra orden y de los sublimes y caritativos principios que la sustentan". El discurso pronunciado con este motivo por el Orador de la logia Moralidad está reproducido íntegro en el Boletín Oficial del Grande Oriente de España [Madrid], II, no 37 (1 ${ }^{\circ}$ noviembre 1872), 6-8.

${ }^{21}$ Para las Hijas del Sol y sus estatutos cfr. Enríquez del Árbol, op. cit., pp. 59-61. Allí se recoge un texto de 1873 bajo el título «Las Hijas del Sol» que dice así: “¿Cuál es el origen de la miseria? La inmoralidad. ¿Cuál es el origen de la inmoralidad? La injusticia. ¿Cuál es el origen de la injusticia? La ignorancia. ¿Cuál es el medio más eficaz para extinguir la ignorancia, la injusticia, la miseria y la inmoralidad? La ilustración de la 
Oficial del Gran Oriente de España, era trabajar por la educación física, intelectual y moral de la mujer, la práctica de la caridad y la beneficencia, la justicia y la protección mutua ${ }^{22}$.

Sin embargo, a pesar del apoyo recibido por la masonería, Las Hijas del Sol -a juicio de Françoise Randouyer- no era una logia de adopción, sino "una asociación femenina laica con unos fines progresistas de educación a la que dieron los masones fundadores, como atractivo, un tinte cosmológico y esotérico"23.

De la misma forma que tampoco lo era la asociación benéfica Las Amigas de los Pobres que algunos hermanos del Gran Oriente de España proponían crear en 1872 a fin de interesar a las mujeres por la institución masónica. A dicha asociación se deberían remitir los fondos de beneficencia de las logias para que ellas se encargaran del reparto y distribución.

Esta forma de entender la masonería fue objeto de controversia y desautorización por parte de los defensores de la masonería tradicional y aséptica, claramente separada de las instituciones profanas ${ }^{24}$. Algunas críticas a estos proyectos las hizo, en febrero de 1873 desde Nueva York, la revista El Espejo Masónico, dirigida por Andrés Cassard ${ }^{25}$.

Sin embargo, por esas fechas, es muy revelador que, a pesar de la oposición de algunos masones, se iniciaron mujeres en cerca de 200 logias masculinas españolas.

La logia Alona de Alicante, entre 1875 y 1878, llegó a contar con 11 masonas en activo. Una de ellas, procedente de Madrid, Palarea de Soto, al solicitar la afiliación hizo constar su iniciación en 1873. En Madrid, en la logia Comuneros de Castilla, llegó a haber 13 hermanas masonas. Una de ellas era Emilia Martin, Esther de simbólico, esposa del escritor, Venerable y fundador de la logia, Nicolás Díaz y Pérez, Viriato. Emilia Martín, en 1892, alcanzaría el grado 18, al igual que otra de las integrantes de la logia, Antonia Martínez de $\operatorname{Das}^{26}$.

También en Madrid, en la logia Legalidad hubo ocho; en la logia 5 de abril del 88, seis; en Hijos del Progreso y La Unión es fuerza, cinco ${ }^{27}$; en Puritanos, cuatro; en

mujer. ¿Quién está llamado a conseguir que la ilustración de la mujer sea una verdad? La masonería que profesa el principio de la verdadera libertad, de la igualdad, de la fraternidad...". Lo firma Confucio gr. 13.

${ }^{22}$ Boletín Oficial del Grande Oriente de España, II, $\mathrm{n}^{\mathrm{O}} 36$ (15 octubre 1872), 3-5, donde están reproducidos los estatutos de Las Hijas del Sol, fechados el $1^{\circ}$ de septiembre de 1872.

${ }^{23}$ Randouyer, "Presencia femenina en las logias españolas (1868-1898)", 603-626. De esta misma opinión es María José Lacalzada, "Hombres y mujeres en la masonería madrileña. Problemática y testimonios (18711917)", en La masonería en Madrid y en España del siglo XVIII al XXI, coord. Ferrer Benimeli (Zaragoza: Gobierno de Aragón, 2004), tomo I, 167-190.

${ }^{24}$ Ya en 1868 se había creado en Madrid el Ateneo Artístico Literario de Señoras por Fernando de Castro. El Ateneo contribuyó a la fundación de la Asociación para la enseñanza de la mujer (1 octubre 1870). Y esta asociación a su vez fundó en marzo de 1882 la revista «Instrucción para la mujer».

${ }^{25}$ El Espejo Masónico IV, no. 4 (febrero 1873): 99 y ss.

${ }^{26}$ Sobre Nicolás Díaz, Fermín Rey Velasco y Antonio Barroso Dávila, Nicolás Díaz y Pérez. Republicano, masón, escritor (1841-1902) (Badajoz: Diputación Provincial, 1986).

${ }^{27}$ Una de ellas, era Clotilde de Araniguria, Isabel de Valois, grado 18 en 1893. 
Fraternidad Ibérica, tres; en Hijos de Riego y El Progreso, dos; y una en las logias Federación e Hijos del Trabajo ${ }^{28}$.

En el cuadro lógico del 4 de marzo de 1888 de Los Amigos de la Virtud, de Lérida, integrado por 48 miembros, encontramos a cuatro mujeres. Y la logia Progreso $n^{\circ} 137$, de Valladolid, bajo los auspicios del Grande Oriente Nacional de España, tenía -el 22 de diciembre de 1888 - cinco masonas, tres con el grado $3^{\circ}$ y dos con el $1^{\circ}$. Dos de ellas eran profesoras $^{29}$.

En Valencia, en la logia Acacia $n^{\circ} 25$ del Grande Oriente de España, había en 1884 una cámara de adopción con ocho masonas y dos lovetonas, al igual que en la logia Valencia $n^{\circ} 119$, en cuya cámara de adopción, en 1891, también había cinco masonas y dos lovetonas. Y en la Estrella del Mediterráneo, de Vilanova del Grao (Valencia), entre 1890 y 1891 se localizan al menos cinco masonas, y dos más en la logia Faro de la Humanidad $n^{\circ} 40$ de la misma localidad.

Otro tanto podríamos decir de las logias Libertad, Fraternidad y Concordia de Barcelona del año 1889, donde también figuran mujeres. En concreto, en la Concordia el Orador era Isabel de Zwonar, gr. 3ㅜ, Fraternidad de simbólico. Tenía 42 años. El venerable de la logia, Enrique Troisi, era su marido ${ }^{30}$.

Pero desde la logia hermana Lealtad de Barcelona escribieron al Gran Oriente Español diciendo que no era regular el procedimiento de conferir cargos a las mujeres en las logias de hombres. Poco después hubo renovación de cargos en la Concordia, e Isabel de $Z_{w o n a r}{ }^{31}$ fue exaltada al grado $9^{\circ}$ y continuó como Oradora, lo que provocó que, en febrero de 1891, la logia Lealtad insistiera ante el Gran Consejo de la Orden denunciando lo que estaba sucediendo en la Concordia ${ }^{32}$. En 1892 Isabel de Zwonar continuaba activa y ocupaba el cargo de secretaria ${ }^{33}$.

En la logia Castra Xulia $n^{\circ} 20$ de Trujillo (Cáceres), Cándida Baltar Bravo tenía el grado $7^{\circ}$ en 1890. Su esposo José Impellitieri y su hermano Aurelio Baltar eran miembros de la logia. Ese mismo año también fue incorporada a la logia Antonia González, Palmira, grado $4^{\text {o34. }}$.

\footnotetext{
${ }^{28}$ Márquez, Poyan, Roldan y Villegas, La masonería en Madrid (Madrid: Avapiés, 1987).

${ }^{29}$ Sus simbólicos eran Acacia, Sahara, Raquel, Eva y Luz.

${ }^{30}$ Sánchez Ferré, "La maçoneria a Catalunya", 165-168.

${ }^{31}$ Isabel de Zwonar, lingüista de profesión, estuvo activa en la masonería española hasta el 17 de octubre de 1902, momento en que se fue a vivir a Marsella. Antes, en 1891, tanto ella como su Venerable y marido, los encontramos primero como honorarios y grado 18 en la logia Les Amis du Devoir y, poco después, como efectivos.

${ }^{32}$ Dicha logia que se constituyó bajo la obediencia del Grande Oriente de España después pasó al Gran Oriente Español y finalmente al Gran Oriente Ibérico.

${ }^{33}$ Lacalzada, Mujeres en masonería (Premià de Mar: Clavell Cultura, 2006). 180-181; Ortiz Albear, Mujeres masonas en España. Diccionario biográfico (1868-1939) (Santa Cruz de Tenerife: Ed. Idea, 2007), 383-385.

${ }^{34}$ Pedro Víctor Fernández Fernández, La masonería en Extremadura (Badajoz: Diputación Provincial, 1989), $167-168$ y $173-175$.
} 
Más sintomático fue lo ocurrido en la logia Emancipación $n^{\circ} 127$ de Sallent (Barcelona) de la que era Venerable José López Montenegro, "maestro laico”. En 1893 ingresaron en la logia su mujer y sus cuatro hijos, tres de ellos mujeres, que se llamaban en consonancia con la ideología de su progenitor- Armonía, Federación y Libertad ${ }^{35}$. El propio Venerable y padre de las criaturas escribió en el Boletín de Procedimientos que los ingresados en la logia (su mujer y sus cuatro hijos) se habían declarado "ateos y anárquicos" ${ }^{\prime 36}$.

Ese mismo año de 1893 Jacinta Navarro Fonseca, Granada, iniciada en la logia Nueva Cádiz $n^{o} 21$ donde alcanzó el grado $3^{\circ}$ y ejerció de secretario, formaba parte de la logia Capitular de Caballeros Rosa Cruz, de Cádiz, que era una logia de militares, en la que volvió a ocupar el cargo de secretario ${ }^{37}$.

Angeles López de Ayala, una de las masonas más célebres de España ${ }^{38}$ y gran impulsora del feminismo en Cataluña ${ }^{39}$, aparece integrada en la logia masculina Constancia de Gracia (Barcelona), donde tuvo los cargos de secretaria y oradora. En 1894 ostentaba el grado 30 del rito francés. Otro tanto ocurre en Madrid, en la logia Amor y Ciencia. En el cuadro de dignidades del año 1892 figuran Matilde Fuentes, Mariana, gr. $3^{\text {o }}$ como $1^{\text {er }}$ Vigilante y Enriqueta Fernández, Fraternidad, gr. $3^{\circ}$ como Orador. El resto eran varones ${ }^{40}$.

El caso de Málaga es bastante característico, pues encontramos a 19 mujeres en seis logias: Verdad y Progreso, Nueva Bética, Columna Social, Virtud, Justicia y Luz. Concretamente la logia Nueva Bética $n^{\circ} 342$ llegó a contar -en 1889- con siete hermanas en un cuadro de 47 masones, sin que les importara ni tuvieran intención de separarse. Más aún tenían acceso a los altos grados como el resto de los hermanos de la logia. Así, María García Ruiz, Astrea, alcanzó el grado 30, mientras que las hermanas por partida doble, Dolores Alba Martín y Josefa Alba Martin, tenían el grado 9. Las tres eran relativamente jóvenes: 32, 21 y 18 años, respectivamente. El 13 de junio de 1890, a raíz de ciertos problemas internos, la Nueva Bética se separó de su obediencia, el Gran Oriente de España, y se proclamó independiente. En diciembre de 1891 integraban el cuadro 12 miembros, de los que tres eran mujeres: Dolores Alba Martín que ya ostentaba el grado 18 y era la

\footnotetext{
${ }^{35}$ El hijo recibió el nombre de París.

${ }^{36}$ Boletín de Procedimientos. Órgano Oficial del Soberano Gran Consejo Ibérico, 14 (28 julio 1893) 13-14.

${ }^{37} \mathrm{Su}$ marido, militar, era el Orador de la logia.

${ }^{38}$ Sobre Ángeles López de Ayala, masona, feminista, librepensadora y espiritista, véase el trabajo de Sánchez Ferré, "Mujer, feminismo y masonería en la Cataluña urbana de la Restauración", en Masonería, política y sociedad, coord. Ferrer Benimeli (Zaragoza: CEHME, 1989), tomo II, 929-945; Ortiz Albear, Diccionario biográfico, 251-254.

${ }^{39}$ Sánchez Ferré, "Els origins del feminisme a Catalunya", Revista de Catalunya 45 (octubre 1990): 33-49. El feminismo en España estuvo muy vinculado con el anticlericalismo y apoyado políticamente por el republicanismo y por amplios sectores de la masonería.

${ }^{40}$ Gaceta Oficial del Grande Oriente Nacional de España, Año VI, no. 60 (15 noviembre 1892): 524.
} 
Tesorera, María García Ruiz, grado 30, Limosnera, y Dolores Zea de Torrubia, gr. 1, orador adjunto $^{41}$.

Pero esto no era lo habitual. En general, cuando en una logia masculina se habían iniciado dos o tres mujeres, se constituía una "columna o cámara de adopción", integrada al principio por hombres y mujeres. Además, era el embrión de una futura logia de adopción cuando el número de iniciadas lo permitía, obteniendo una mayor autonomía que, en algunos casos, llegó a ser absoluta, al independizarse de su logia madre y, a veces, incluso, de la propia obediencia.

Aunque no siempre una cámara de adopción acababa convirtiéndose en logia de adopción. Quizá uno de los casos más paradigmáticos fue el de Lealtad de Barcelona ${ }^{42}$ que, ya en 1879, tenía una cámara de adopción integrada por dos mujeres, Aurora Rosa Clavé de Ferrer, Mariana de Pineda, profesora de música, esposa de Conrado Ferrer miembro de la misma logia; y Dolores Fernández de Aranda, Sara. Un par de años después, en 1881, eran ya ocho. Hasta 1885 llegaron a ser iniciadas no menos de 11. Sin embargo, no hay constancia documental de que constituyeran una logia de adopción ${ }^{43}$. Una posible explicación radica en que ninguna de ellas había alcanzado el grado $3^{\circ}$ y carecían, por lo tanto, de las maestras necesarias. Parece ser que la logia Lealtad de Barcelona no tenía prisa en conferir grados a las mujeres. Otra posible justificación -según María José Lacalzada- es que estamos ante mujeres independientes y de buena posición social que les permitía cierta autonomía y ocupar el tiempo en otras actividades quizá más atractivas ${ }^{44}$.

Una de estas era Clotilde Cerdá, hija del ingeniero urbanista Ildefonso Cerdá, artífice del ensanche de la ciudad de Barcelona. Había sido iniciada en la masonería a la edad de 18 años. Era profesora arpista de prestigio, conocida en el mundo del arte como “Esmeralda Cervantes". Su primer concierto público tuvo lugar en la Exposición de Viena de $1873^{45}$.

Algo parecido sucedía con la logia Constante Alona de Alicante ${ }^{46}$, que el 4 de mayo de 1883 iniciaba a tres profanas: Mercedes de Vargas, Juana de Arco; Juana Dagnino,

\footnotetext{
41 María Pinto Molina, La masonería en Málaga y provincia (último tercio del siglo XIX) (Granada: Universidad, 1987).

42 Era una logia que llegó a contar con 74 miembros vinculados a la industria, comercio y profesiones liberales.

${ }^{4}$ Sánchez Ferré, La lògia Lealtad. Un exemple de Maçoneria catalana (1869-1939) (Barcelona: Ed. Alta Fulla, 1985), 182. Conocemos la profesión de algunos de los integrantes de la «cámara de adopción» de la logia Lealtad, en especial cabe destacar dos profesoras de música - una de ellas de arpa-, tres profesoras sin especificar y dos artistas.

${ }^{44}$ Lacalzada, Mujeres en masonería, 130.

${ }^{45}$ En la logia Tinerfe $n^{\circ} 114$ de Santa Cruz de Tenerife figura en 1882-1889 como miembro Honorario (Manuel de Paz Sánchez, Historia de la Francmasonería en Canarias (1739-1936) (Las Palmas: Cabildo Insular de Gran Canaria, 1984), 805).

${ }^{46}$ Perteneció al Gran Oriente de España hasta 1899, que reconoció la autoridad del recién creado Gran Oriente Español (Vicente Sampedro Ramo, "La masonería alicantina ante las crisis intermasónicas de 1886-1889 y el
} 
Mariana Pineda; y Juana Velasco, Cristina. Asistieron al acto 44 masones y otras cuatro mujeres masonas. Al año siguiente eran iniciadas tres más. Con estas, la cámara de adopción de la Constante Alona se incrementó hasta 12 masonas. Lo curioso es que en la tenida del 28 de abril de 1884 fueron iniciados simultáneamente dos hombres y dos mujeres. Tras el discurso del Orador intervino la hermana Juana de Arco [Mercedes Vargas], ilustrando a las nuevas masonas en los deberes que debían observar y en las obligaciones que habían contraído como iniciadas. Y les recomendó especialmente "la instrucción, base fundamental para cumplir los deberes de buenas hijas, buenas esposas y buenas madres, punto de partida para que la mujer sea lo que debe ser" 47 .

En 1888 formaban parte de la logia 23 masonas. En total, entre 1883 y 1892 pertenecieron a la Constante Alona, de Alicante, 38 mujeres, siendo quizá la más célebre la conocida escritora y librepensadora Rosario de Acuña y Villanueva, Hipatía ${ }^{48}$. Sin embargo, la cámara de adopción no llegó a constituirse en logia de adopción porque el Gran Maestre y Soberano Comendador no lo autorizó con la excusa de que se estaba reestructurando la obediencia y preparando una ley sobre las logias de adopción.

Otro tanto debió de ocurrir con la logia Creación $n^{\circ} 159$ de Barcelona, que en 1884 estaba compuesta por 67 miembros de los que al menos 12 eran hermanas ${ }^{49}$; y -tambiéncon Luz del Porvenir $n^{\circ} 179$, de Loja (Granada), constituida regularmente el 19 de marzo de 1883 bajo los auspicios del Gran Oriente Nacional de España. Inició a la primera mujer, Concepción Ruiz Mata, Judit, el 7 de noviembre de 1884. Cuatro años más tarde, en la cámara de adopción de dicha logia había ya diez mujeres, todas ellas grado $1^{\circ}$. No había ninguna con el grado $3^{\circ}$ y tampoco hay constancia de que llegara a constituirse en logia de adopción $^{50}$.

Lo mismo parece ser sucedió con la logia Los Diez Hermanos de Cartagena, "regularmente constituida bajo los auspicios de la Masonería Activa Independiente

nacimiento del Gran Oriente Español", en Masonería, revolución y reacción, coord. Ferrer Benimeli (Alicante: Fundación Juan Gil-Albert, 1990), tomo II, 633-648.

${ }^{47}$ Mercedes Vargas de Chambó, iniciada el 4 de mayo de 1883, era escritora y colaboradora habitual de $L a$ Humanidad, órgano de la logia alicantina. En sus escritos manifiesta una personalidad marcada por las relaciones familiares de madre, esposa e hija. El año de su iniciación eran miembros de la Constante Alona su esposo, Carlos Chambó, Julio César, y su hija Petra, Carlota Corday, así como su yerno, el médico Juan Dagnino Gimbernot. A partir de 1884 fue nombrada Oradora honoraria ad vitam del taller.

${ }^{48}$ Sobre Rosario de Acuña, entre otros, José Bolado García, "Rosario de Acuña: Palabra y testimonios en la causa de la emancipación femenina", en La masonería española y la crisis colonial del 98, coord. Ferrer Benimeli (Zaragoza: Gobierno de Aragón, 1999, t. I). 65-81.

${ }^{49}$ Dos eran «viudas de masones» y otra «esposa de masón». Entre las profesiones una figura como «maestra de escuela».

${ }^{50}$ Los simbólicos eran Judit, Celeste, Juana de Arco, Marietta, Luz, Staël, Violeta, Zaida, Mariana Pineda, Estrella. La ocupación de todas ellas era «sus labores» y todas estaban unidas con masones de la misma logia por lazos de parentesco. Francisco López Casimiro, Masones en Granada. Último tercio del siglo XIX (Granada: Comares, 2000), 218. 
Universal" 51 , en cuyo cuadro lógico de 1891 figuraban 46 miembros, de los que 13 eran mujeres, iniciadas todas ellas a finales de 1890. Las profesiones de estas últimas, según consta en dicho cuadro, eran en 11 casos "su sexo" y en dos "profesoras" 52 . Dadas las vicisitudes de esta particular logia, tampoco llegaron a constituirse en logia de adopción.

Pero, a pesar de los casos anteriores, lo más normal era que la cámara de adopción terminara convirtiéndose en logia de adopción, si bien hay que insistir que dichas logias de adopción españolas -salvo el propio título- tenían muy poco en común con las establecidas en Francia en el siglo XVIII o durante la época bonapartista.

Una de las primeras en constituirse como tal fue la logia de adopción Minerva, de Madrid, fundada en 1873 a partir de la logia Porvenir. Según el Boletín Oficial del Grande Oriente de España, en 1881 todavía contaba con "un número respetable de señoras, esposas en su mayor número de hermanos nuestros", y se distinguían "por la seriedad de sus trabajos" $" 53$.

Un caso particular lo constituye la logia Hijas de Memphis, que existió en Madrid y que llegó a reunir -al menos- a 14 mujeres entre 1877 y 1880. Fue dada a conocer por Françoise Randouyer a partir de la revista masónica francesa La Chaîne d'Union ${ }^{54}$. Dicha revista en su número de julio-agosto de 1880 recogía en su crónica de noticias del extranjero que la condesa de Apratxin había sido iniciada en la logia Fraternidad Ibérica de Madrid, según el rito masculino y añadía que era la primera mujer iniciada en España. Con este motivo, todas las integrantes de la logia de adopción Hijas de Memphis, desde la «Soberana Maestra» a la Guarda Templo, firmaron una carta indicando sus cargos ${ }^{55}$

\footnotetext{
${ }^{51}$ Esta logia nació el 1 de enero de 1877 -dependiente del Grande Oriente de España-y fue creada por diez masones disidentes de diferentes talleres. Y lo hizo esgrimiendo el símbolo de la unidad y fraternidad. Pero, al año siguiente, se proclamó independiente. El 31 de enero de 1891 dirigió un largo manifiesto a todas las logias de España en el que se dice que el peor mal que aquejaba a la masonería española era la desunión: "No es racional, no es lógico que los masones, que son hermanos desde el momento en que ven la luz y sin distinción de raza, color, religión, ni pueblo, se miren como extraños dentro de una misma nación, hablando una misma lengua, profesando iguales costumbres y sintiendo idénticas aspiraciones, por consecuencia funesta de la incalificable cuestión de obediencias". A continuación, analizaba la situación de las múltiples obediencias masónicas españolas y se preguntaba cuáles eran las causas de esta situación. Su respuesta fue contundente. Por un lado, "la ambición o las miras personales" de las altas instancias masónicas. Por otro, "el aislamiento casi absoluto que entre las logias existe". Lo curioso es que como solución proponían crear una nueva obediencia. Ante el fracaso de su idea universalista, la logia se constituyó bajo los auspicios de la "Masonería Activa Independiente Universal". En 1894 se acercó al Gran Oriente Español del que llegó a formar parte con el número 216, abatiendo columnas en 1896.

52 José Antonio Ayala, La masonería en la región de Murcia (Murcia: Ed. Mediterráneo, 1986), 246-260 [Edición corregida y aumentada, Santa Cruz de Tenerife, Ed. Idea, 2009], 311-329].

${ }^{53}$ Boletín Oficial del Grande Oriente de España [Madrid], X, no. 42 (1880) 624. La logia Porvenir $n^{\circ} 56$ en esas fechas estaba bajo la obediencia del Grande Oriente Nacional de España y habían sido fundada el 20 de marzo de 1871.

${ }^{54}$ La Chaîne d'Union [Paris], juillet-août 1880.

${ }^{55}$ Soberana maestra, secretaria, dos inspectoras, $\mathrm{M}^{\mathrm{a}}$ de Elocuencia, Tesorera, $\mathrm{M}^{\mathrm{a}}$ de Ceremonias, Limosnera $\mathrm{y}$ Guarda Templo.
} 
dirigida a la Chaîne d'Union para desmentir que dicha condesa fuera la primera mujer iniciada en la masonería en España, ya que ellas existían desde 1877. Es decir, hacía tres años. Lo curioso del caso es que, en esos años, no había en Madrid ninguna logia que se llamara Memphis de la que se pudieran proclamar Hijas de Memphis. Más aún, la Gran Logia Simbólica Española de Memphis y Mizraim no se constituyó hasta el año 1889. Y entre las diez logias fundadoras, todas ellas madrileñas, ninguna tenía como título distintivo el de Memphis $^{56}$. Da la impresión de ser una logia femenina con total autonomía que se regía por sí sola, sin depender de ninguna logia masculina e, incluso, de ninguna obediencia.

Volviendo a la condesa de Apratxin, motivo de la polémica anterior, efectivamente había sido iniciada en junio de 1880 en la logia Fraternidad Ibérica, de Madrid, bajo la obediencia del Gran Oriente Nacional de España. Se llamaba Julia Rubio, adoptó el simbólico Budha y era esposa de un miembro de esa logia ${ }^{57}$, de la que era Venerable el escritor Eduardo Caballero de Puga, simbólico Moreto ${ }^{58}$. Asistieron al acto más de 80 masones de diferentes logias y se utilizó el Rito Escocés Antiguo y Aceptado. Unos días después de su recepción como masona, la condesa Apratxin-Batthiany estaba en Paris ${ }^{59}$. Y es de nuevo La Chaîne d'Union la que se ocupa de ella:

Nous avons eu la faveur de la voir et de causer avec elle. Elle était porteuse d'une lettre d'introduction du Grand Secrétaire du Grand Orient National d'Espagne. Cette dame nous a inspiré la meilleure estime et la plus grande considération. Elle nous a montré son diplôme qui est parfaitement en règle. Notre Soeur et son mari, qui est également Maçon, nous ont expliqué qu'elle avait été reçue au même titre qu'un profane et qu'elle avait été initiée en loge bleu de Maçonnerie ayant passé par toutes les épreuves du véritable Maçon ${ }^{60}$.

\footnotetext{
${ }^{56}$ Ferrer Benimeli, "Implantación de logias y distribución geográfico-histórica de la masonería española", en La masonería en la España del siglo XIX, coord. Ferrer Benimeli (Valladolid: Junta de Castilla y León, 1987), tomo I, 57-216. De todas formas, el adoptar como título distintivo Hijas de... no siempre significaba origen o dependencia de otra logia, como ocurre con Hijas de los Pobres, Hijas de Acacia, Hijas de la Libertad, Hijas del Progreso, etc., al igual que sucedía en las logias masculinas, como en Hijos de la Constancia, Hijos del Trabajo, Hijos de Hiram, Hijos de Rhea, etcétera.

${ }^{57}$ En el Calendario y Mapa Masónico para 1884, publicado en Madrid por la logia Fraternidad Ibérica $n^{\circ} 90$, figura L. Rubio, simbólico Finsgue, grado $4^{\circ}$, del Cuerpo Diplomático y con residencia en París.

${ }^{58}$ Francisco Márquez Santos, "Eduardo Caballero de Puga y la masonería liberal moderada", en La masonería en la España del siglo XIX, 649-655, El libro de Actas de la logia Fraternidad Ibérica $n^{\circ} 15$ recoge con detalle la ceremonia de iniciación. De ella se ocupa también Lacalzada, "Hombres y mujeres en la masonería madrileña", 167-190.

${ }^{59}$ Posiblemente para la publicación de su novela L'une ou l'autre (París: Ed. Dentu, 1880).

${ }^{60}$ La Chaîne d'Union [Paris] (août-septembre 1880) 234. Reproducido por Hivert-Messeca, Gisèle et Yves, « Comment la Franc-Maçonnerie vint aux femmes », 247.
} 
La revista -tal vez como respuesta indirecta a la carta de la logia Hijas de Memphisreprodujo también la carta del Gran Secretario - que no era otro que Eduardo Caballero de Puga-, que empezaba así:

... la Condesa Julia $\mathrm{A}^{* * *}$ ha sido la primera iniciada en el Gran Oriente Nacional de España, la primera iniciada en toda forma, como si fuera un hombre...

El que se repita dos veces la expresión "la primera iniciada" en el Gran Oriente Nacional de España tal vez llevó a la revista parisina al equívoco, al decir que había sido "la primera mujer iniciada en España", identificando el Gran Oriente Nacional de España con la masonería española, desconociendo la existencia de otras obediencias y de logias independientes o autónomas.

Unos años más tarde, en 1885, Caballero de Puga, en el Gran Capítulo Provincial de Barcelona, aludiendo a la costumbre masónica que había dado a la masonería un aspecto exclusivamente masculino, dijo que las mujeres estaban "en la plenitud de sus derechos y al declararlas miembros de la institución, no se hacía sino admitir el espíritu de construcción que traen a este mundo todos los seres humanos". Y en consecuencia se las iniciaba con todo el simbolismo heredado de la masonería operativa. Y aconsejaba aceptar a las mujeres desde los 23 años y que fueran "preferentemente esposa, hija, hermana o viuda de masón" 61 .

La logia de adopción La Creación, de Mahón en Menorca, fue fundada en 1884. Su Venerable Maestra era Encarnación Valls, esposa del general Carmona, que a su vez era el Venerable de la logia Hermanos de la Humanidad, de la que dependía la primera. Tres de los hijos de este matrimonio eran lovetones: Arturo de seis años; Adalberto, de ocho; y Margarita, de diez. En 1888 componían la logia de adopción 15 mujeres, la mayor parte esposas o familiares de masones. Y 12 de ellas tenían el grado $3^{\circ}$. Un año después falleció la Venerable y fue elegida para sustituirle Catalina Hernández, la nueva esposa del general y Venerable Carmona. Hemos localizado 33 mujeres pertenecientes a esta logia, la única de adopción existente en las islas Baleares en su época ${ }^{62}$. En los papeles impresos de La Creación, que trabajaba a la gloria del Gran Arquitecto del Universo, figuran dos lemas: «Libertad, Igualdad, Fraternidad» (al lado izquierdo) y «Abnegación, Virtud, Modestia» (al derecho $)^{63}$.

\footnotetext{
${ }^{61}$ Libro de Actas de las tenidas de la Gran Logia Simbólica del Grande Oriente Nacional de España, 15 de junio de 1885, citado por Randouyer, "Presencia femenina precoz en las logias españolas", 610.

${ }^{62}$ En enero de 1890 eran 19 las integrantes de la logia.

${ }^{63}$ Francisco Sanllorente Barragan, La masonería en las Islas Baleares 1800-1940 (Mallorca: Miquel Font, 1999), 100-102; Juan José Morales. "La masonería en Menorca", en La masonería en la España del siglo XIX, tomo I, 383-400; Morales. "La mujer en la masonería menorquina del siglo XIX", en Masonería, revolución y reacción, tomo II, 657-685.
} 
La logia de adopción Hijas de los Pobres, de Madrid, fue fundada el 27 de noviembre de 1887. Su Venerable Maestra, Suceso Sánchez Martín, simbólico Rebeca, en esas fechas tenía el grado 18. Anteriormente había pertenecido a la logia Legalidad, también de Madrid, bajo la obediencia de la Gran Logia Unida de España ${ }^{64}$. También era miembro de esta logia Ángeles López de Ayala, una de las más prestigiosas representantes de la masonería femenina española ${ }^{65}$.

En 1889 existía en Madrid la logia de adopción Hijas del Progreso, de la que era Venerable Maestra Patrocinio Nicolás y Oradora la famosa Rosario de Acuña y Villanueva, "la más importante representante del feminismo librepensador y emancipador de la mujer" 66 .

El 31 de marzo de 1890 se constituyó en Valencia la primera logia de adopción, bajo el título de Hijas de la Acacia, y procedente de la logia capitular Acacia $n^{\circ} 25$ de la misma ciudad. Integraban este taller nueve mujeres, todas con el grado $3^{067}$. Su primera Venerable, Julia Fos Clavero, durante la ceremonia de instalación, tuvo palabras de elogio hacia la actitud firmemente democrática del Gran Oriente Español.

En 1891 la logia Valencia $n^{\circ} 119$, que desde su fundación tenía dos mujeres en su cuadro lógico, se planteó crear una cámara de adopción. En noviembre de 1891 dicha cámara ya estaba integrada por siete miembros, de los que cinco eran mujeres vinculadas por lazos familiares con el Venerable Amador Sempere, concretamente su mujer Elena López Muñoz, África, y sus cuatro hijas, Ángela, Natividad, Isabel y Francisca. Las dos últimas formaban parte de las cinco lovetonas de la cámara. El 16 de diciembre, la cámara de adopción se transformó en logia de adopción, tomando el nombre de Hijas de la Unión. Contaba con nueve hermanas, que en 1893 eran ya 15. En junio de 1894 la logia recibió el título de Augusta, en reconocimiento a su labor. Por este motivo se celebró una tenida solemne de colocación de la banda preceptiva. El acto tuvo lugar en el templo de Federación Valentina $n^{o} 42^{68}$. En recuerdo se hicieron una fotografía -que todavía se conserva- en la que aparecen 12 hermanas y dos lovetonas. La Venerable era Rita Oller, América, hasta ese momento Inspectora del taller ${ }^{69}$.

\footnotetext{
${ }^{64}$ Ortiz Albear, Las mujeres en la masonería, 101-102.

${ }^{65}$ Ortiz Albear, Las mujeres en la masonería, nota 18.

${ }^{66}$ Ortiz Albear, Las mujeres en la masonería, nota 48 y Lacalzada de Mateo, "Mercedes de Vargas y Rosario de Acuña: el espacio privado, la presencia pública y la masonería (1883-1891)”, en Prototipos e imágenes de la mujer en los siglos XIX y XX, coord. Amparo Quile y Teresa Sauret (Málaga: Universidad-Atenea, 2002), 43-72.

${ }^{67}$ Sus simbólicos eran Paz, Ester, Luz, Antigua, Verdad, Dafne, América, Sara y Caridad.

${ }^{68}$ Sampedro, "La masonería valenciana y su proyección en la sociedad: confrontación ideológica, redes de sociabilidad e interrelación política (1870-1939)", en Masonería e Ilustración. Del siglo de las luces a la actualidad (Valencia: Muvim, en prensa).

${ }^{69}$ Aunque en la fotografía solo aparecen los nombres simbólicos sabemos que estos corresponden a Rita Oller (Venerable), América, gr. 6º Natividad Sempere, Juana de Arco, gr. 4\% ; Isabel Sempere, Palmira, gr. $3^{\circ}$; Francisca Sempere (secretaria), Rosario de Acuña, gr. $3^{\circ}$; Remedios Boigues, Salud, gr. $3^{\circ}$; Carmen Delhoro,
} 
Un caso particular lo constituyó la logia femenina Audacia $n^{\circ}$ 80, de Herrera (Sevilla), cuya instalación tuvo lugar el 16 de abril de $1892^{70}$. La Venerable Maestra Juana J. Moreno, simbólico $\mathrm{Paz}$, tenía el grado $7^{\circ}$, y en su discurso inaugural animó a las hermanas a buscar el "resplandor de la verdad" y la "destrucción del oscurantismo". La secretaria tenía el grado $4^{\circ}$. Lo más curioso es que formaron la logia directamente con la autorización del Gran Maestre de la Gran Logia Simbólica de Memphis y Mizraim, Ramón Moreno y Roure, desvinculada de toda tutela masculina. Prácticamente todas las componentes del taller estaban casadas con masones de la logia Minerva de la misma localidad. Fruto de estos matrimonios fueron las dos primeras lovetonas, que recibieron los nombres simbólicos de Igualdad y Lucifer "a ruegos de su padre"71.

El hecho de que Audacia optara por una radical independencia de las logias masculinas y que adoptara el mencionado título distintivo fue criticado por la Gran Logia de Cuba, que acusó a sus integrantes de arrogancia. La respuesta de la Venerable Maestra, Juana J. Moreno, fue que el nombre dado a la logia, lejos de pretencioso, ellas lo consideraban "como una obligación, como un deber masónico". Y, a su vez, atacó a la Gran Logia de Cuba diciendo que era una lástima que perdiese el tiempo censurándolas y no lo invirtiese excitando a sus talleres a que "nos ayudasen a sostener las escuelas laicas" que iban a inaugurar brevemente en una población de 1.500 vecinos ${ }^{72}$.

Las logias de adopción creadas en Puerto Rico lo hicieron a través de las cuatro obediencias españolas que trabajaban en la isla, pues la Gran Logia Soberana de Puerto Rico no admitía la participación de mujeres en sus organismos. Por esta razón, al igual que luego ocurriría en Cuba, la integración femenina a las logias se implantó a través de la masonería española. El sistema fue el mismo que en la España metropolitana. El primer paso fue aceptar a mujeres en las logias masculinas, mientras que el segundo consistió en crear logias de adopción compuestas solo por mujeres.

El año clave fue 1890. En la lista de miembros de la logia Caballeros del Silencio $n^{o}$ 340 de San Juan, perteneciente al Gran Oriente de España, había tres nombres de mujeres, las tres de grado $2^{\circ}$, las tres casadas con miembros de la logia, y de profesión "su casa". A saber, eran: Gloria Seguí de Buls, Raquel; Rosa Lendo de Arzuaga, Castilla; y Carmen M. de Maturana, Marietta. Meses después se extinguió esa logia y se constituyó una nueva, Caballeros de San Juan $n^{\circ} 279$, esta vez bajo los auspicios del Gran Oriente Nacional de España, en la que aparecían entre los siete fundadores Gloria Seguí de Buls -ya grado 3-

María del Olvido, gr. $3^{\circ}$; Angela Sempere, Victoria, gr. $3^{\circ}$; Isabel Blanco Polanco, Amistad, gr. $1^{\circ}$. De momento ignoramos los que corresponden a Africa, Lorena, Oceanía y Florinda.

${ }^{70}$ Estaba integrada en la Gran Logia Simbólica del Rito de Memphis y Mizraim.

${ }^{71}$ Enríquez del Árbol, "Masonería y feminismo: la logia Audacia de Herrera (Sevilla) 1892-1896", en Homenaje a la profesora $M^{a}$ Dolores Tortosa Linde, coord. R. Morales Rayar (Granada: Universidad, 2003), 151-168.

${ }^{72}$ En dicha escuela sería muy notable la colaboración de las hermanas de la logia Audacia. 
como Segundo Vigilante, y su marido Félix J. Buls como Primer Vigilante. Al poco se unía a la logia otra esposa de masón, Rosa Ernestina S. de Montañez, Libertad de simbólico ${ }^{73}$.

El mismo año, en la logia de San Juan, Luz de Oriente $n^{\circ} 280$, también del Gran Oriente Nacional de España, entre sus fundadores se encontraba Lorenza Cruz de Cortijo, simbólico Venezuela ${ }^{74}$, grado $3^{\circ}$, con el cargo de Oradora. Tenía 26 años. También figuran mujeres en las logias Fidelidad $n^{\circ} 76$, de San Juan (Gran Logia Simbólica de Memphis y Mizraim); Luz del Porvenir $n^{\circ}$ 163, de Salinas (Gran Oriente Español); y Alianza $n^{\circ} 297$, de Vieques (Gran Oriente Nacional de España), que constituyó en 1893 una Sociedad Benéfica de Damas integrada por las esposas e hijas de los miembros de la logia ${ }^{75}$.

Respecto a las logias de adopción de Puerto Rico conocemos la existencia, al menos, de cinco en la última década del siglo XIX, lógicamente antes de la independencia de la isla que tuvo lugar en 1898 a raíz de la guerra de los Estados Unidos contra Cuba y Puerto Rico ${ }^{76}$. Pero solo se conserva documentación de dos de ellas (Reina Regente $n^{\circ} 4$, de Guayama, y Protectora $n^{\circ} 3$, de San Juan) y noticias indirectas de las otras tres.

La logia de adopción Reina Regente, conocida también como «Jardín del Edén», fue fundada en la ciudad de Guayama a iniciativa de la logia Legalidad Española $n^{\circ} 67$ de la misma ciudad y admitida en el Gran Oriente Español el 15 de agosto de 1890. La ceremonia de instalación tuvo lugar el 20 de septiembre. En un principio componían la logia seis mujeres. $\mathrm{Y}$ al regresar una a la península fueron admitidos tres masones varones procedentes de la logia madre. María del Olvido de Borbón, infanta de España, prima segunda del rey Alfonso XII ${ }^{77}$, fue proclamada «protectora» de la logia. Y como iniciativa novedosa en la historia de la masonería femenina, en mayo de 1893 fueron iniciadas siete «domesticas» de entre 20 y 42 años $^{78}$, posiblemente empleadas en los mismos hogares que sus hermanas de logia ${ }^{79}$.

La instalación de la logia de adopción Protectora de San Juan $n^{\circ} 3$, de San Juan de Puerto Rico, auspiciada por el Gran Oriente Nacional de España, tuvo lugar el 21 de octubre de 1891, y la logia patrocinadora fue Caballeros de San Juan $n^{\circ} 27$. Estaba integrada por 11 mujeres $^{80}$, de las que solo la Gran Maestra y la Primera Inspectora ostentaban grados superiores, el $7^{\circ}$ y $9^{\circ}$ respectivamente. Todas las demás habían sido

\footnotetext{
${ }^{73}$ Ayala, La masonería de obediencia española en Puerto Rico en el siglo XIX (Murcia: Universidad, 1991), 118-119.

${ }^{74}$ Posiblemente de origen venezolano.

${ }^{75}$ Ayala, "La masonería de obediencia española", 120.

${ }^{76}$ Creación $n^{o} 2$ y Protectora $n^{\circ} 3$ de San Juan, Reina Regente $n^{\circ} 4$ de Guayama, Protectora de Borinquen s/n de Humaçao y Perlas Boriqueñas $n^{\circ} 6$ de Mayagüez.

77 Fue iniciada en España en 1888 (Ortiz Albear, "Mujeres masonas en España”, 123-124 / Ayala, "La masonería de obediencia española", 121-122).

${ }^{78}$ Cinco eran solteras, una casada y una viuda.

${ }^{79}$ Ayala, "La masonería de obediencia española", 122.
} 
iniciadas para poder constituir la logia de adopción y solo poseían el grado $1^{\mathrm{o}}$ de aprendiz. Siete eran relativamente jóvenes, entre los 22 y 29 años. También aquí acabaron ingresando cuatro masones de la logia madre Caballeros de San Juan. La profesión de todas ellas era «su casa» y la mayoría estaba emparentada con masones.

De la logia Creación $n^{\circ} 2$ apenas sabemos nada. Tan solo se alude a ella en un documento y ni siquiera se indica la ciudad donde estaba establecida, ni la obediencia a la que pertenecía. De la logia Protectora de Borinquen no sabemos el número, aunque sí la ciudad, Humacao. El carecer de número de inscripción suscita la duda de si llegó a establecerse formalmente. De todas formas, ése era el proyecto de la logia madre Corazones Perfectos $n^{\circ} 117$, también de Humacao, bajo la obediencia del Gran Oriente Nacional de España. Con este fin inició en noviembre de 1891 a Manuela Guzmán Dilucidado, señora de Bustelo, simbólico Malinche, para ser el embrión de dicha logia en unión de "tres damas más de estos valles en la actualidad pendientes de recepción"81.

De la logia de adopción Perlas Borinqueñas $n^{\circ} 7$ de Mayagüez se ocupa el Boletín Oficial del Gran Oriente Español, en su número del 1 de enero de 1893, anunciando su admisión en la Federación del Gran Oriente Español ${ }^{82}$. Fue auspiciada por la logia Borinquen $n^{\circ} 81$ de la misma ciudad y que previamente había iniciado a diez señoras.

Esta situación de las diferentes masonerías españolas, que llevaban 20 años iniciando a mujeres -al menos desde 1871-, experimentó un profundo cambio desde 18911892. Tal vez influidas por lo ocurrido en Francia, a partir de la iniciación de María Deraismes en 1882 y de la reacción de la masonería francesa que obligó a Maria Deraismes a ser "pour douze ans une maçonne sans loge -según expresión de Yves Hivert-Messeca-, malgré les tentatives de frères, notamment de Georges Martin pour la faire affilier à un atelier masculin" 83 .

En España, con la presencia de mujeres en cerca de 200 logias masculinas solo en el último tercio del siglo $\mathrm{XIX}^{84}$, daba la impresión de que se había logrado resolver un problema secular. Sin embargo, la creación de logias de adopción supuso un giro y marcha atrás, sobre todo cuando en 1891 el Grande Oriente Nacional de España y en 1892 el Gran Oriente Español publicaron sendos reglamentos sobre esas logias de adopción intentando "reconducir" la situación y regularizar la situación de la mujer en la masonería.

\footnotetext{
${ }^{80}$ Los nombres simbólicos eran la mayoría topónimos (Europa, Antillas, América, Borinquen, Numancia) y el resto con alusiones patrióticas y bíblicas (Raquel, Marta, Esther, Patria, Acacia, Libertad).

${ }^{81}$ Ayala, "La masonería de obediencia española", 120.

${ }^{82}$ Boletín Oficial del Gran Oriente Español, Año V, $\mathrm{n}^{\circ} 64$ (1 ${ }^{\circ}$ enero 1893) 20. Con esta misma fecha también fue admitida en la obediencia del Gran Oriente Español la logia Estrella de Occidente $n^{\circ} 167$ de Cabo Rojo, Puerto Rico.

${ }^{83}$ Hivert-Messeca, Encyclopédie de la Franc-Maçonnerie, 208. Igualmente, Hivert-Messeca, Gisèle et Yves, Comment la Franc-maçonnerie vint aux femmes, especialmente el capítulo XI dedicado a Maria Deraismes, 221-253.

${ }^{84}$ Más exactamente 184 logias incluidos once capítulos y un triángulo.
} 
El decreto del 25 de marzo de 1891, firmado por J. M. Pantoja, Gran Maestre y Gran Comendador interino del Grande Oriente Nacional de España ${ }^{85}$, va precedido de un preámbulo suficientemente expresivo:

Sabed: que deseando el Grande Oriente Nacional de España corregir, como patriarca que es de la familia Francmasónica española ${ }^{86}$, las corruptelas que solían cometerse iniciando y admitiendo señoras en las logias, cosa prohibida en todo Rito; pero queriendo al propio tiempo dignificar y enaltecer a la más hermosa mitad de la raza humana, se ha servido constituir y organizar como rama especial, separada e independiente de la Francmasonería Masculina, y Nos sancionar, el Rito de adopción o de señoras ${ }^{87}$.

En virtud de este decreto proclamado como ley "en todas las provincias españolas peninsulares, ultramarinas y en las Colonias", las iniciaciones de señoras deberían hacerse en lo sucesivo con sujeción a esta norma y por los rituales especiales del rito que "oficialmente publique el Gran Oriente".

Tras la reglamentaria invocación "A la Gloria del Gran Arquitecto del Universo", el nuevo Rito sancionado en su mismo título expresaba con claridad el cambio de orientación experimentado: "Rito de adopción o de señoras constituido como rama especial y completamente separada de la Francmasonería masculina”. Consta de siete capítulos y 33 artículos.

En el artículo primero se dice que el Rito de adopción o de señoras era una rama especial de la Orden Francmasónica. Y, en consecuencia, "no es una asociación política ni religiosa" $"$. El artículo segundo define el objetivo del Rito de adopción: "practicar la virtud y la beneficencia, propagar la instrucción, dignificar al bello sexo y hacer de las afiliadas verdaderos modelos de distinción, sensatez y buenas costumbres". Además, se señalan como los principales medios de acción:

La creación, sostenimiento e inspección de colegios, asilos de huérfanos y ancianos, hospitales, propagación de la idea del matrimonio como base moral, formación de dotes para doncellas pobres y auxilio de los heridos en campaña.

\footnotetext{
${ }^{85}$ El decreto va dirigido "a todos los Maestres francmasones, logias, capítulos, cámaras superiores, Grandes Delegados, y a cuantos los presentes vieren y entendieren”. José María Pantoja fue el tercer Gran Maestre y Gran Comendador del Grande Oriente Nacional de España. A la muerte de su antecesor, Juan Antonio Seoane, ocurrida el 31 de enero de 1887, fue elegido Teniente Gran Comendador y Gran Maestre Adjunto, cargo que ejerció hasta que en las elecciones celebradas el 25 de julio de 1893 salió elegido, manteniendo ambos cargos ad vitam, como era tradición en esa obediencia.

${ }^{86}$ El Grande Oriente Nacional de España fue constituido con arreglo a la ley de Asociaciones el 7 de febrero de 1869.

${ }^{87}$ Boletín Oficial del Grande Oriente Nacional de España, Año V, nº 90 (30 marzo 1891), 1-6.

${ }^{88} \mathrm{Se}$ añade que como institución ha de observar con toda escrupulosidad las leyes de la nación en que vive y ha de existir y funcionar "en nuestra patria" bajo el patronato del Grande Oriente Nacional de España.
} 
Es decir que se transformaba a las logias de adopción en una especie de sociedad paramasónica de beneficencia. Más aún, a esta orientación de carácter estrictamente benéfico, se añade en el artículo $5^{\circ}$ la supeditación absoluta al Gran Comendador, ya que ninguna hermana podía tener taller, "si no está autorizada por Carta Patente del Gran Comendador, ni dar recepciones más que en presencia de un Venerable Maestro, delegado por el Grande Oriente, que tenga su domicilio en la misma localidad".

Esta subordinación masculina se acentua en el artículo $7^{\circ}$, en el que se dice que la Gran Maestra, así como las hermanas censora, secretaria y tesorera, estarían siempre auxiliadas por un Venerable Maestro la primera, y por diferentes hermanos las demás. Y todavía se matiza más al decir que estos cargos deberían recaer siempre "en hombres de alguna edad, de intachable moralidad y reconocido talento".

$\mathrm{Y}$ un tercer aspecto a destacar en este afán de control y supeditación es lo que incluía el artículo 15. A saber: que ninguna candidata sería recibida si por virtud de la ley estaba bajo la potestad de otra persona, "salvo el consentimiento de aquella de quien dependa civilmente" 89 . Tampoco podían ser recibidas antes de haber cumplido los 18 años.

Asimismo, el 15 de agosto de 1892, la otra obediencia con gran implantación en el país, el Gran Oriente Español y en su nombre el Gran Consejo de la Orden para España, provincias y posesiones de Ultramar, publicaba también una ley de adopción en su Boletín Oficial correspondiente ${ }^{90}$.

La justificación seguía, en parte, las pautas utilizadas por el Gran Oriente Nacional de España. En concreto, la situación era esta:

Resulta que algunas señoras en posesión de grados del Rito Escocés Antiguo y Aceptado, obtenidos en logias y capítulos irregulares, solicitan afiliación en nuestros talleres; que otras pretenden ingresar en nuestra Orden llamando a las puertas de la cámara de aprendiz, y que estas cámaras, o niegan la iniciación sin otro recurso, o la otorgan, resistiéndose en muchos casos a comunicar a las iniciadas la palabra sagrada y negándolas siempre un puesto en la cadena mística ${ }^{91}$.

Y abundando en esta diversidad de criterios, constataban que había:

Muchas logias que no solo niegan la iniciación escocesa a las profanas, sino que pretenden cerrar sus templos a las ya iniciadas en nuestro Rito y que además se hallan inscritas en los Cuadros de miembros activos de un Taller simbólico federado, fundándose para ello en que la Federación tiene sus logias de adopción, y toda señora que no pertenezca a una de estas es, para el caso, irregular.

\footnotetext{
${ }^{89}$ Quedaban exentas de esta restricción "las investidas del derecho de administrar sus bienes, los de sus maridos o los de sus hijos".

${ }^{90}$ Boletín Oficial del Gran Oriente Español IV, no. 145 (15 agosto 1892): 145.

${ }^{91}$ Boletín Oficial del Gran Oriente Español IV, no. 145 (15 agosto 1892): 145.
} 
Tras esta constatación de rechazo a lo que es habitual en España y se venía practicando desde hacía 20 años - mucho antes de la fundación del Gran Oriente Español ${ }^{92}$ , es decir, que en las logias masculinas se iniciaran y formaran parte con los mismos derechos ${ }^{93}$ miembros del sexo contrario, finalmente añaden que: "El Rito Escocés Antiguo y Aceptado que practica nuestra Federación no admite en su seno a la mujer, sino que la designa un Rito especial llamado de adopción".

Teniendo en cuenta estas y otras razones de interés general masónico, la Asamblea General del Gran Oriente Español aprobó y el Gran Consejo de la Orden en su nombre, sancionó y promulgó la ley de adopción que consta de un solo capítulo dividido en 19 $\operatorname{artículos}^{94}$.

El primero era ya suficientemente expresivo: "Ningún Taller de la Federación puede iniciar, afiliar, regularizar ni conceder aumentos de salario en el Rito Escocés Antiguo y Aceptado, a la mujer".

El artículo segundo aparentemente estaba en contradicción con el anterior, pues distinguía bien entre cámara de adopción y logia de adopción y admitía logias [masculinas] en las que sí se pudieran iniciar, afiliar o regularizar hermanas. Pero solamente en aquellas ciudades (Valles) donde no existiera logia de adopción. Y solo lo podrían hacer en cámara de adopción "en la forma establecida para la masonería auxiliar por el Rito de adopción y sus estatutos y reglamentos generales". Resulta interesante el calificativo que se hacía de la masonería de adopción: masonería auxiliar.

Por el artículo tercero se limitaba a seis hermanas el máximo de la cámara de adopción. Al pasar de ese número deberían solicitar del Gran Consejo de la Orden la carta constitutiva de logia de adopción.

En los artículos siguientes se prohibe recibir en los talleres visitadoras, a no ser en la cámara de adopción o en tenidas blancas. Y en ningún caso se permite en las logias de adopción recibir como visitadores a los hermanos aprendices y compañeros.

En el artículo diez se dice que las logias de adopción no tienen voz ni voto en la Asamblea General de la Federación ${ }^{95}$.

En el artículo 15 se hace constar que las hermanas que poseyeran grados del Rito Escocés Antiguo y Aceptado, incluido los filosóficos (con sus correspondientes certificados o títulos) en adelante, solo tendrían valor a título honorífico, pudiendo canjearlos por los equivalentes del Rito de adopción.

Y el artículo 17 culmina y cierra, por así decir, la nueva orientación:

\footnotetext{
${ }^{92}$ Que había tenido lugar en 1889.

${ }^{93}$ Incluidos los altos grados y cargos.

${ }^{94}$ La ley de la obediencia rival, el Grande Oriente Nacional de España, del año anterior, constaba de 7 capítulos y 33 artículos.

${ }^{95}$ Recordemos que, en años anteriores, en algún caso, habían participado directamente incluso en la elección del Gran Maestre y Soberano Gran Comendador.
} 
Las logias simbólicas, en cuyos cuadros figuren hermanas masonas, procederán desde esta fecha a efectuar la debida separación de hermanos y hermanas, formando la cámara o logia de adopción, según corresponda por el número de hermanas inscritas.

Ese mismo año de 1892, Eduardo Caballero de Puga, Moreto ${ }^{96}$, publicaba un ritual que llevaba este significativo título: Francmasonería femenina. Grado Primero del Rito de adopción o de señoras creado como rama especial y completamente separada de la Francmasonería Masculina ${ }^{97}$. En él decía que la francmasonería femenina era una rama especial y aparte de la masculina.

Pero este Caballero de Puga, Gran Secretario del Grande Oriente Nacional de España, que firmaba el decreto y reglamentos sobre las logias de adopción en 1891 y que parecía ser su ideólogo y redactor, al igual que de los posteriores rituales, era el mismo que en 1885 había dicho que las mujeres estaban en plenitud de sus derechos, por lo que declarándolas miembros de la masonería se cumplía el espíritu de la propia masonería ${ }^{98}$.

La pregunta que surge espontánea es: ¿por qué se dio este cambio tan radical en las dos obediencias masónicas que, en esos años, tenían mayor implantación en España? Dejando de lado otras interpretaciones especialmente vinculadas al anticlericalismo ${ }^{99}$, que en este caso no estimo demasiado válidas, creo que es fundamental tener presente lo que estaba ocurriendo en Francia. Sobre todo, dado el influjo ejercido por la masonería francesa -especialmente la del Gran Oriente de Francia-, tanto en el Grande Oriente Nacional de España como, sobre todo, en el Gran Oriente Español.

En Francia, a raíz de la iniciación de Maria Deraismes el 14 de enero de 1882, se entabló un largo proceso no solo en la Grande Loge Symbolique Ecossaise, conocida igualmente como Grande Loge Symbolique de France, sino también en el Suprême Conseil de France y en el Grand Orient de France. Proceso que culminaría el 4 de abril de 1893 con la creación de la Grande Loge Mixte Ecossaise le Droit Humain y el 23 de febrero de 1895 con el de la Grande Loge de France.

El hecho es que la implantación de los reglamentos y ley de logias de adopción tanto por el Grande Oriente Nacional de España como por el Gran Oriente Español supuso -en general- un serio intento por reducir y controlar la presencia de la mujer en las logias masculinas españolas, al mismo tiempo que se potenciaban las logias de adopción, que eran

\footnotetext{
${ }^{96}$ En 1883 era el Venerable de la logia capitular Fraternidad Ibérica $n^{\circ} 90$ de Madrid.

${ }^{97}$ Publicado en la Tipografía de Dionisio de los Ríos, 1892. Cfr. un análisis del pensamiento de Caballero de Puga en 1892 (Ortiz Albear, "La integración de la mujer en la masonería española a través del rito de adopción (1868-1939)", Studia Historica. Historia Contemporánea 23, no. monográfico dedicado a "Los Estudios sobre la historia de la masonería hoy”, coord. Alberto Valín Fernández, 131-152.

${ }^{98}$ Nota 61.

${ }^{99}$ Françoise Randouyer apunta al contexto político-social y religioso del momento y en particular a la polémica constante con la Iglesia católica. Nota 23.
} 
degradadas a la categoría de "auxiliares" de la masonería. Si bien es cierto que este criterio no fue compartido por otras obediencias.

Así, por ejemplo, el Soberano Gran Consejo General Ibérico del Rito Antiguo y Primitivo Oriental de Memphis y Mizraim se opuso radicalmente. Y el 15 de mayo de 1892 afirmaba taxativamente que "la mujer tiene derecho a toda nuestra atención y los Orientalistas la queremos a nuestro lado con iguales deberes y derechos que los hombres". Y ponían como ejemplo la logia Audacia de Herrera (Sevilla) -de la que nos hemos ocupado antes ${ }^{100}$ - compuesta exclusivamente de señoras, así como otras logias de su obediencia en las que había hermanas iniciadas, pues la "adopción" -añadían- "solamente la debemos dar a menores o a los ancianos" $" 101$.

Y un año después, el mismo Soberano Consejo reconocía que "al considerar a la mujer en la masonería con los mismos derechos que el hombre, según se consignan en nuestros reglamentos, representamos la extrema izquierda de los movimientos masónicos españoles"102.

Abundando en esta defensa de la igualdad de la mujer en la masonería, el Boletín de Procedimientos, del 14 de octubre de 1893, publicaba un artículo titulado «La mujer y la masonería», en el que se decía que:

[...] si la masonería no reconoce fronteras, razas, ideas, religiones, etc., creemos que tampoco debe hacer excepción de los sexos. Se dice y se publica en escritos por muchos masones que la mujer no se debe admitir en la masonería, y sobre todo que formar logias de señoras es un escándalo, una herejía. Hemos pensado sobre este asunto, y pensando argumentos de todas clases, resulta que no hay razón para excluir a la mujer de los trabajos masónicos. Es más estamos persuadidos de que es necesario el concurso del bello sexo y que es un factor importante la mujer para que la masonería se desarrolle y llene el objeto de sus trabajos y aspiraciones ${ }^{103}$.

Ante actitudes tan dispares no es fácil calibrar el cambio experimentado en general en la masonería española. Pues, aunque disponemos de algunos datos significativos, no se pueden generalizar. Da la impresión de que las otras obediencias no siguieron el modelo restrictivo del Grande Oriente Nacional de España y del Gran Oriente Español: Matilde Fuentes fue Oradora en la logia Amor y Ciencia de Murcia en 1892, si bien esta logia pertenecía a una escisión del Grande Oriente Nacional de España, el llamado Grande

\footnotetext{
${ }^{100}$ Notas 71, 72 y 73 .

101 Boletín de Procedimientos del Soberano Gran Consejo Simbólico del Rito de Memphis y Mizraim [Madrid], IV, no 20 (15 mayo 1892) 3-5. Esta nota fue hecha a raíz de un discurso pronunciado por la Hermana Isabel Galindo de Torres en la logia Isis Lucentina, de Lucena (Córdoba).

${ }^{102}$ Morales Ruiz, "La mujer en la masonería menorquina del siglo XIX, 663.

${ }^{103}$ Boletín de Procedimientos del Soberano Gran Consejo Simbólico del Rito de Memphis y Mizraim V, no. 19 (14 octubre 1893): 5-6.
} 
Oriente Nacional de Ros [GONER]. En 1893 Dolores Arniches desempeñaba el cargo de Segunda Vigilante en la logia masculina Electricista $n^{\circ} 85$ de Murcia, perteneciente también al GONER. Y en 1894 Antonia Fernández era Oradora de la logia Osiris de Sevilla [GONER] e Isabel Galindo y Osuna de Torres, Juana de Arco, lo era de la logia Audacia $n^{o}$ 90 de Herrera (Sevilla), logia que en esas fechas pertenecía a la Gran Logia Simbólica de Memphis y Mizraim.

Por su parte Ana Carvia era secretaria adjunta en la logia masculina Regeneración de Cádiz [GONER], antes de fundar en 1895 la logia de adopción Hijas de la Regeneración, ambas bajo la obediencia del Gran Oriente Ibérico. La singularidad de esta logia -destaca Natividad Ortiz Albear ${ }^{104}$ - es que a pesar de haberse creado como logia de adopción en la reunión del 27 de julio de 1895 decidieron constituirse bajo el Rito Escocés Antiguo y Aceptado, por lo que previamente procedieron a la disolución de la logia de adopción. El motivo principal utilizado fue que la mayoría de sus integrantes habían sido iniciadas en dicho rito escocés antiguo y aceptado.

Amalia Carvia fue la Venerable Maestre y Ana Carvia la Primera Vigilante. En sus orígenes integraban la logia al menos 17 hermanas. Pero lo más curioso es que, tras la fundación de Hijas de la Regeneración, las hermanas Carvia siguieron ocupando los cargos de secretaria y oradora de la logia masculina adoptante Regeneración ${ }^{105}$.

Las Hijas de la Regeneración, en la tenida del 14 de abril de 1896, con motivo del aniversario de la toma de la Bastilla, enviaron una felicitación al cónsul francés, que tuvo su pronta respuesta.

En otros casos se sigue constatando la presencia de mujeres en logias masculinas. Así, Dolores Navas Delgado, Astrea, y Consuelo Delgado de Navas, Libertad, eran miembros de la logia Estrella Flamígera $n^{\circ} 46$, de Córdoba, en igualdad con los varones, figurando en una lista -en 1892- para el proyecto de Montepío del Gran Oriente Español, como "obreros activos". Para muchas mujeres masonas seguía siendo muy importante tener los mismos derechos y las mismas obligaciones que los hombres.

Como contrapartida, el Gran Oriente Español, una vez aprobada la ley de adopción, creó en La Habana (Cuba), entre 1891 y 1895, tres logias de adopción: Hijas de la Libertad, e Hijas de Yara en 1893, Hijas del Progreso en 1895, y otra más en Buenos Aires (Argentina), Hijas de Osiris ${ }^{106 .}$

De estas, la más representativa es Hijas de la Libertad, constituida en 1891 por iniciativa de Manuel Samper Palma, Venerable y fundador de la logia Zaragoza, de La Habana y “Gran Inspector General de la Orden”. Aunque la idea de la fundación venía ya

\footnotetext{
${ }^{104}$ Ortiz Albear, "Diccionario de mujeres”, 42-43; Lacalzada, "Mujeres en masonería”, 158-161.

105 Nota 17.

${ }^{106}$ En el siglo XX hay constancia -al menos- de la fundación, por el Gran Oriente Español, de las logias de adopción Hijas de la Acacia (1922) en Buenos Aires; Amor (1931) en Madrid; Renacer (1932) en Cartagena; Reivindicación (1932) en Madrid; Delfos (1934) en Barcelona; y el triángulo Luz (1934) de Barcelona.
} 
de 1885 , fue en 1887 cuando se propuso en su taller la iniciación de 17 mujeres, esposas de otros tantos miembros de la logia Zaragoza. Pero el proyecto fracasó y hubo que esperar hasta 1891. Manuel Samper viajó a España y se trajo los poderes necesarios para fundar la logia de adopción. En agradecimiento al gran interés que puso Manuel Samper, simbólico Libertad, las integrantes de la nueva logia decidieron adoptar el nombre de Hijas de la Libertad. La logia fue instalada con seis mujeres y en poco más de un año se incorporaron otras cinco. La primera Venerable Maestra fue la esposa de Manuel Samper, Lucía de la Vega de Samper, que había sido iniciada durante el viaje que hizo con su marido a España en 1889. En la memoria de la logia, correspondiente al año 1891, se recogen las palabras de Manuel Samper, síntesis de su pensamiento: "Sin la mujer, la masonería estaba estancada y no iba a ningún lado"107.

El influjo de Manuel Samper también se extendió a la logia de adopción Hijas de Yara, de La Habana, constituida en 1893. La única noticia de su fundación procede esta vez del Boletín Oficial del Grande Oriente Nacional de España en su número del 30 de abril de $1893^{108}$.

Esta presencia femenina en la masonería española metropolitana y de ultramar, en su doble vertiente de logias masculinas o logias de adopción, fue desconocida o ignorada en Francia durante 25 años hasta que llamó la atención de Blanche Muratet, quien, después de realizar un viaje por España, destacó extrañada en su logia -el 14 de octubre de 1896- que "le Grand Orient Espagnol admet la femme à l'initiation au même titre que l'homme". Unos meses después, el Bulletin de la Franc-maçonnerie Mixte le Droit Humain, en su número de febrero de 1897, recogía la noticia bajo el título «La Maçonnerie Mixte en Espagne»):

Notre Soeur Blanche Muratet nous a communiqué des documents interessants sur la femme dans la Franc-Maçonnerie en Espagne.

Il résulte des renseignements recueillis par notre Soeur, lors d'un voyage qu'elle fit en Espagne, que le Grand Orient Espagnol admet la femme à l'initiation maconnique, au même titre que l'homme.

Le Grand Orient Espagnol, a dans son organisation maçonnique, ce qu'il apelle des Triangles. Partout ou il n'est pas possible de constituer de Loges, faute de Maîtres Maçons en nombre suffisant, on forme un Triangle. Le Triangle n'exige que trois Maîtres Maçons, qui reçoivent les pouvoirs suffisants de la Puissance Supèrieure pour initier des Apprentis, des Compagnons, et même des Maîtres, afin de former par la suite une Loge régulièrement constituée.

\footnotetext{
${ }^{107}$ José Manuel Castellano Gil, La masonería española en Cuba (La Laguna: Ayuntamiento, 1986), 163.

${ }^{108}$ Boletín Oficial del Grande Oriente Nacional de España VII, no. 140 (30 abril 1893): 8.
} 
Ce modus faciendi est très rationnel et constitue un puissant moyen de développement maçonnique, qui pourrait s'il était adopté en France, rendre à l'ordre les plus grands services... ${ }^{109}$.

Ese mismo año la logia Le Droit Humain $n^{o} 1$ de París se enteraba que en España existían cinco logias de mujeres pertenecientes al Gran Oriente Español ${ }^{110}$. Y para saber si las integrantes de esas logias estaban realmente iniciadas con los medios de reconocimiento de la masonería universal o simplemente con los de las logias de adopción, algunos componentes del Derecho Humano hicieron un viaje por España en 1897 y tomaron contacto, entre otros, con Isabel Zwonar ${ }^{111}$, a la que pidieron les redactara un informe. Y es allí donde contaron su propia historia masónica. Decían que su iniciación había tenido lugar en una logia masculina y había durado cuatro horas enteras con la asistencia de 400 hermanos procedentes de otras logias de Madrid, siendo recibida en la Concordia como miembro activo de pleno derecho ${ }^{112}$.

Cuando se habla o escribe de las masonas españolas se suele insistir en el factor librepensador de algunas de ellas: Rosario de Acuña, Angeles López de Ayala, Belén Sárraga, Amalia y Ana Carvia, Amalia Domingo Soler... ${ }^{13}$ o en el espiritista de Macias Pons de Pares ${ }^{114}$, que son algunas de las que constituyen el panteón de masonas ilustres o "masonas de excepción" 115 . Pero se olvida de que, además de ellas, existen otras muchas con planteamientos diferentes y por supuesto mucho menos radicales.

Así, y sin olvidar que en España, logias y obediencias seguían trabajando a la gloria del Gran Arquitecto del Universo, y que la primera de las preguntas que debían responder en la cámara de reflexión era “¿Qué debe el hombre a Dios?”"116, nos podemos encontrar con discursos como el de Isabel Galindo y Osuna de Torres, simbólico Juana de Arco, leído el día de su iniciación en la logia Nueva Uter de Rute (Córdoba):

Si es verdad que el Dios que aquí se adora es el Dios Caridad, Justicia y Progreso, sépase que para ese Dios y para los que lo siguen, habrá siempre en mi corazón la

\footnotetext{
${ }^{109}$ Bulletin de la Franc-Maçonnerie Mixte le Droit Humain [Paris] (février 1897), 17. Blanche Muratet, iniciada en Le Droit Humain $n^{\circ}$ 1, afiliada al Libre Examen el 26 de febrero de 1902, fue una de las fundadoras de la Nouvelle Jérusalem en 1906, ambas de la Grande Loge de France.

${ }^{110}$ Bulletin de la Franc-Maçonnerie Mixte le Droit Humain (1903): 75-77.

111 Nota 31.

112 Nota 32.

113 Pedo F. Álvarez Lázaro, Masonería y librepensamiento en la España de la Restauración (Madrid: Universidad Comillas, 1985); Suzanne Marza. Premières manifestations de la Franc-Maçonnerie féminine en Espagne au XIXe sicle (1868-1898) (Aix-en-Provence, Septentrion, 1997).

${ }^{114}$ Lacalzada, "Mujeres en masonería", 117.

${ }^{115}$ Así las denomina Suzanne Marza, "Premières manifestations", 284-350.

${ }^{116}$ Las otras dos eran: ¿Qué se debe a sí mismo? ¿Qué debe a sus semejantes?
} 
suficiente fe para adorar al primero, y el sincero afectuoso cariño para los segundos ${ }^{117}$.

En esta logia, formada exclusivamente por hombres, el discurso iba dirigido a sus "queridos hermanos"118.

En otros casos se carga el acento en una lectura feminista de estos discursos ${ }^{119}$. Pero una atenta lectura de estos nos lleva también a un trasfondo más realista en el que la mujer queda reducida al papel de esposa y madre. Basta recordar que la mayoría de las masonas eran esposas, hermanas, hijas o viudas de masones. Más aún, da la impresión de que a veces el objetivo de la iniciación de mujeres o la formación de logias de adopción pretendía una emancipación de la mujer de la tutela eclesiástica. Pero también se puede interpretar como un mayor control masculino, no ya solo en el hogar, sino en las actividades o contactos externos.

Resulta sintomático que el mayor porcentaje de "profesiones" de las masonas españolas corresponde a "sus labores", "su casa" o "su sexo". Son amas de casa más o menos burguesas con cierta conciencia social íntimamente ligada con la educación y beneficencia.

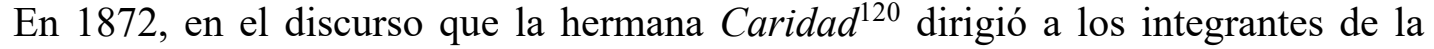
logia Teide $n^{\circ} 58$ de Santa Cruz de Tenerife, en el acto de inauguración de un Templo, dijo -entre otras cosas-: "No veo entre vosotros otros seres de mi sexo y eso me causa una amarguísima pena”. Y añadía:

En el mundo masónico también las mujeres tenemos una misión que cumplir: la cabecera de la pobre enferma y los cuidados del tierno niño corresponden a la mujer masona; y en este sentido nuestros servicios pueden ser oportunos y provechosos. Por eso yo os excito a todos para que abráis los ojos de vuestras hijas y esposas a la Verdadera Luz acercándolas a las puertas de vuestro Templo que por débiles y humildes que sean los recursos de la mujer, también debe ser estimado su grano de arena para formar parte del edificio que se levanta aquí a la Gloria del Gran Arquitecto del Universo.

Concluía con este consejo:

\footnotetext{
${ }^{117}$ Boletín de Procedimientos 2 (11 enero 1891): 4-5.

${ }^{118}$ A los pocos días de su iniciación fue nombrada Limosnera.

${ }^{119}$ En esta línea van algunas publicaciones recientes de María José Lacalzada y en especial Mujeres en masonería.

${ }^{120}$ Procedía de la logia Bética de Málaga donde había sido iniciada. Su presencia en Tenerife era debida a que su padre, también masón, había sido trasladado a esa isla.
} 
Os recomiendo trabajéis para que algún día veamos formada una fuerte columna, compuesta de vuestras hijas y esposas, que sean luz y virtud en la sociedad, consuelo y alegría en el hogar domestico ${ }^{121}$.

En la mayor parte de los casos, las mujeres se inician en las logias a las que pertenecen sus maridos o hermanos, que son los que -además- debían de pagar sus cuotas de iniciación y demás gastos derivados de pertenecer a la masonería, salvo en aquellos -que son los menos- en los que las mujeres tenían una profesión específica e independencia económica. Protección patriarcal y protección económica con una añadida visión egoísta y necesidad de la mujer, que algunos masones ponían de manifiesto sin rubor, como el Hermano F.S., Empecinado de simbólico, al que alaba el Boletín Oficial del Grande Oriente de España por su proyecto de establecer una logia de adopción "plantel de matronas virtuosas y puras", cuyo objetivo era la mujer, "esa criatura adorable y llena de ternura colocada por el Gran Arquitecto del Universo cerca del hombre para hacer más dichosa su vida y menos penosos los azares que tan frecuentemente le atormentan"122.

Necesidad y control de la mujer en el hogar y en la masonería. Y finalmente nepotismo y endogamia, pues la obtención de cargos y grados en algunos talleres de adopción es proporcional al poder de los maridos en la propia logia, como hemos visto en varias ocasiones en las que el marido era Venerable de la logia madre y su mujer, la Venerable de la logia de adopción. Incluso en uno de ellos, al morir la esposa del Venerable y volverse a casar, la segunda mujer pasaba a ocupar el puesto de Venerable que tenía su primera cónyuge ${ }^{123}$.

Los masones pretendían la regeneración de la mujer porque era la base de la familia y de la sociedad. La misión de la masonería era la emancipación del género femenino a través de la instrucción, la educación y la práctica de la caridad o beneficencia, pero sin perder de vista "sus deberes de esposa y madre".

Respecto a la profesión de las mujeres iniciadas en la masonería no siempre queda especificada en la documentación. Pero un pequeño muestreo, realizado por Natividad Ortiz Albear, puede ser ilustrativo. De un total de 151 masonas de finales del siglo XIX (1871-1898) del que se conoce el oficio, cerca del centenar se dedica a "sus labores, casa o sexo", 15 son artistas o actrices y otras tantas profesoras o maestras, seis escritoras y otras seis domesticas ${ }^{124}$, empleadas y propietarias, tres en cada caso; dos profesoras de música,

\footnotetext{
${ }^{121}$ Boletín Oficial del Grande Oriente de España II, no. 38 (15 noviembre 1872): 6-8.

${ }^{122}$ Boletín Oficial del Grande Oriente de España II, no. 40 (15 diciembre 1872): 9.

123 Nota 62.

${ }^{124}$ Este es un caso particular - no representativo- de una logia de Puerto Rico que inició el mismo día a seis domesticas, se supone que de otras tantas masonas de la misma logia. Nota 78.
} 
modistas y matronas, y una labradora ${ }^{125}$, industrial, bordadora y lingüista ${ }^{126}$. Como se puede apreciar la actividad desarrollada dentro de casa era claramente mayoritaria.

Siguiendo la costumbre de la masonería española, las masonas al iniciarse elegían su nombre simbólico que, en cierto sentido, nos acerca a su forma de ser o pensar. Uno de los más adoptados fue el de una santa católica y patriota, Juana de Arco, en 34 casos, solo superada por otra santa laica y patriota, Mariana de Pineda en 50. Hay seis Luisa Michel, tres Carlota Corday, dos Maria Antonieta, una Madame Roland, Lamballe e Isabel de Valois y ocho María Estuardo.

La mayor parte, casi un centenar, prefirieron nombres relacionados con virtudes: Caridad, Fe, Esperanza, Humildad, Firmeza, Constancia, Modestia, Rectitud, Verdad...

En un grupo de aspectos ideológicos más progresistas podemos incluir las que optaron por simbólicos como Libertad, Democracia, Ciencia, Emancipación, Justicia, Progreso, República, Regeneración, Razón, Tolerancia, Paz...

De entre los nombres bíblicos los más frecuentes son Sara, Judit, Esther, Rebeca, Eva, Debora, Susana, Magdalena... Y entre las mujeres célebres de la antigüedad encontramos a Hipatia, Palmira, Cornelia, Cleopatra, Talia, Safo, Oriana, Minerva...

Un apartado también elegido por algunas masonas es el geográfico, con nombres de países: América, Asia, África, Colombia, Venezuela, España, Grecia, Italia, Cuba... o de ciudades como Granada, Barcelona, Lérida, Plasencia, Zaragoza, Vigo... ${ }^{127}$.

\section{Conclusión o síntesis final}

1. En España la masonería estuvo severamente prohibida y perseguida desde 1738 a 1868 tanto por la Inquisición y la Iglesia católica -por motivos religiosos-, como por los gobiernos -por motivos políticos-.

2. España fue el último país europeo en el que se introdujo la masonería de forma institucionalizada. Y lo hizo a raíz de las libertades constitucionales (reunión, expresión y asociación) obtenidas con la revolución de Cádiz de 1868.

3. A partir de entonces proliferaron rápidamente las logias y obediencias, tanto en la España metropolitana como en ultramar.

\footnotetext{
125 Tal vez propietaria de tierras de campo.

${ }^{126}$ Ortiz Albear, Diccionario biográfico, 59-60. A su vez Suzanne Marza, "Premières manifestations", 258, da 104 como profesión "su casa, sus labores o su sexo", 33 profesoras o maestras, 13 artistas o actrices, nueve escritoras o publicistas, nueve propietarias, dos industriales, una costurera, una bordadora, una planchadora...
} 
4. Entre 1869 y 1898 se fundaron 1750 logias pertenecientes a 20 obediencias diferentes, si bien fueron seis las más importantes.

5. La primera iniciación documentada de mujeres data de 1871, es decir 11 años antes de la polémica iniciación de María Deraismes en Les Libres Pensaeus de Pec. Y la primera logia de adopción conocida fue de 1873, cuando en Francia, Italia y Portugal habían prácticamente desaparecido.

6. Entre 1871 y 1939, final de la guerra civil e inicio del franquismo, hay constancia documental de al menos 732 mujeres iniciadas. Corresponden 586 al siglo XIX (1871-1898) y 146 al siglo XX (1900-1939). Estos datos son meramente orientativos, pues calculamos que solo disponemos del $60 \%$ de la documentación real.

7. Proporcionalmente el número de mujeres es mínimo, teniendo en cuenta que de los 82000 registros de masones existentes en el Banco de datos del CEHME, 54000 corresponden al último tercio del siglo $\mathrm{XIX}^{128}$.

8. Algunos ejemplos pueden ser significativos: Aragón de 387 masones, solo tres son mujeres; Baleares, 33 mujeres de un total de 994 masones; Galicia, 37 de 1310; Murcia 42 de 1947; Puerto Rico, 24 de 1832.

9. La admisión e iniciación de mujeres se hizo en 180 logias masculinas diferentes y en igualdad de condiciones que el hombre. El Rito más utilizado fue el Escocés Antiguo y Aceptado.

10. Las mujeres masonas se integraban y formaban parte como miembros activos en logias masculinas que, en la práctica, se convirtieron en logias mixtas.

\footnotetext{
${ }^{127}$ Sobre el valor y metodología de los nombres simbólicos. Randouyer, "Ideología masónica a través de los nombres simbólicos", 425-439; Randouyer, "Les noms symboliques des maçons espagnols. Une approche objective des valeurs d'un groupe social", Chroniques d'Histoire Maçonnique 29-30 (1980): 56-61.

${ }^{128}$ En la estadística que reproduce Nicolás Díaz y Pérez en La Francmasonería Española. Ensayo HistóricoCrítico de la Orden de los Francmasones en España desde su origen hasta nuestros días, publicada en Madrid el año 1894, da los siguientes datos en la página 630: Grande Oriente Nacional de España, 20000; Gran Oriente Ibérico, 22000; Gran Logia Simbólica Independiente de Sevilla, 4600; Gran Oriente Español, 16000; Soberano Gran Consejo General Ibérico, 2300. Total 64900. Y añade que en este número están incluidas 2200 hermanas, unas formando logias de adopción y, otras, la mayoría, confundidas en las logias de hermanos. Concluye matizando que la mitad de los que figuran en el estado anterior "están hoy en sueños".
} 
11. En estas logias, las mujeres -a veces- constituían una columna o cámara de adopción como paso previo a las logias de adopción, aunque no siempre las primeras llegaban a constituirse en las segundas.

12. En casos especiales, tanto en las cámaras de adopción como en las logias de adopción había presencia masculina para poder completar el número reglamentario, por falta o ausencia de hermanas.

13. Las mujeres desempeñaban cargos de responsabilidad en las logias de mayoría masculina, como el de orador, vigilante y secretario. E, incluso, figuraban entre las fundadoras de logias masculinas.

14. Las mujeres masonas alcanzaban grados superiores al $3^{\circ}$, como el $9^{\circ}, 18^{\circ}, 24^{\circ}, 30^{\circ}$ e, incluso, el $33^{\circ}$ en algún caso, y formaban parte de logias capitulares.

15. Entre 1871 y 1891 la ausencia de directrices claras y de tradición masónica en España, así como el inicio de la emancipación femenina en la sociedad, facilitaron la iniciación de mujeres en la masonería.

16. La multiplicidad de obediencias masónicas en la España del XIX hizo que existiera una profunda disparidad de criterios entre los propios masones. Frente al rechazo de unos, estaba la visión más aperturista de otros.

17. Para unos la mujer quedaba reducida al papel de esposa y madre. Sin embargo, otros la elevaban a la categoría de miembro activo, reconociendo a la iniciada los mismos derechos y deberes que al resto de hermanos de la logia.

18. Una gran parte de masonas eran esposas, hermanas, hijas o viudas de masones. Y su extracción social era de la media y baja burguesía.

19. En algunos casos existía un claro nepotismo endogámico con vinculación directa y familiar en los cargos. Por ejemplo, el Venerable de una logia masculina y la Venerable de la logia de adopción eran marido y mujer del mismo matrimonio.

20. Había logias de adopción que se independizaron de la logia madre e, incluso, de la obediencia. 
21. Frente a una minoría de masonas librepensadoras, había otras muchas con una ideología más tradicional y conservadora, como se deduce de sus propios discursos y de la "profesión" de gran parte de ellas: "sus labores", "su casa", "su sexo".

22. A veces el objetivo de la iniciación de mujeres o la formación de logias de adopción buscaba la emancipación de la mujer de la tutela eclesiástica.

23. Se constata un feminismo militante no solo en las mujeres sino en gran parte del sector masculino, que a veces da la sensación de un intento patriarcal de los propios masones de control de la mujer en el hogar y fuera de él a través de la masonería.

24. La ideología más generalizada [en masones y masonas] es la regeneración de la mujer en cuanto base de la familia y de la sociedad, y la emancipación del género femenino a través de la instrucción, educación y beneficencia, pero sin perder de vista "sus deberes de esposa y madre".

25. Eran representativos de la ideología de las masonas los nombres simbólicos elegidos en el momento de la iniciación, siguiendo la costumbre española de la época.

26. A partir de los primeros reglamentos y de la ley de adopción de los años 1891 y 1892, promulgados por el Grande Oriente Nacional de España y el Gran Oriente Español, se experimentó un claro retroceso respecto a la aceptación de la mujer en la masonería en igualdad de condiciones que el hombre.

27. Parece ser que fue consecuencia de lo ocurrido en Francia con María Deraismes entre 1882 y la posterior fundación en 1892 de la Orden Mixta Internacional El Derecho Humano.

28. Estos reglamentos y ley de adopción fueron un intento por reducir y controlar la presencia de la mujer en las logias masculinas españolas al mismo tiempo que se potenciaban las logias de adopción, convertidas en meros "auxiliares" de la masonería.

29. La nueva ideología y orientación impuesta a las logias de adopción las reduce a una especie de sociedad paramasónica de beneficencia, separada de los hombres y bajo el férreo control del Gran Maestre y Soberano Gran Comendador. 
30. Sin embargo, otras obediencias se opusieron radicalmente, como la Gran Logia Simbólica del Rito de Memphis y Mizraim, que siguió considerando a la mujer en la masonería con los mismos derechos que el hombre, autoproclamándose como la "extrema izquierda" de la masonería o movimientos masónicos españoles.

31. Más aún se negó a admitir la expresión "adopción” que, por su carácter protector, era solo apropiada para menores y ancianos, añadiendo que, si la masonería no reconocía fronteras, razas, ideas o religiones, tampoco debía hacer excepción de los sexos.

32. Esta presencia femenina en logias españolas fue desconocida o ignorada en Francia durante 25 años, hasta que en 1896 llamó la atención de Blanche Muratet, quien ofreció un interesante informe en el Bulletin de la Francmaçonnerie Mixte le Droit Humain, reconociendo que "le Grand Orient Espagnol admet la femme à l'initiation au même titre que l'homme".

33. Paralelamente, hubo un intento de control o inspección desde París por parte del Derecho Humano, que envió una delegación a España en 1897 para ver si las mujeres españolas estaban iniciadas con los medios y reconocimiento de la Francmasonería universal, o simplemente con los de las logias de adopción.

34. La actitud de unas y otras obediencias hizo que a finales del siglo XIX se incrementara el número de logias de adopción tanto en la metrópoli como en ultramar, especialmente en Cuba y Puerto Rico.

35. Pero la crisis finisecular derivada de la guerra con EE.UU. y la pérdida de las últimas colonias: Filipinas, Cuba y Puerto Rico, hizo que la masonería española se autodisolviera acusada de ser la causante de dicha pérdida.

\section{Bibliografía}

Álvarez Lázaro, Pedro F. "La mujer masona española: una minoría marginada en un colectivo marginal”. En Las mujeres en la construcción del mundo contemporáneo. Coordinado por Teresa Marín Eced y María del Mar del Río Andrés. Cuenca: Publ. Diputación Provincial, 2002.

Ballesteros Rosa. "En busca de un espacio autónomo. El caso de las logias femeninas en Portugal”. En Las mujeres y el poder. Representaciones y prácticas de la vida. 
Coordinado por Ana I. Cerrada Jiménez y Cristina Segura. Madrid: Al-Mudaina, 2000.

Bolado, José. "Rosario de Acuña: Palabra y testimonio en la causa de la emancipación femenina". En La masonería española y la crisis colonial del 98. Coordinado por José Antonio Ferrer Benimeli. Zaragoza: CEHME, 1999.

Cuartero Escobés, Susana. "La mujer y la masonería". Revista de Extremadura 4 (eneroabril 1991): 67-72.

Enríquez del Árbol, Eduardo. "La masonería española y la mujer en el sexenio democrático (1868-1874)". Anuario de Historia Contemporánea 14 (1987-1991): 49-66.

Enríquez del Árbol, Eduardo. "Masonería y feminismo: la logia 'Audacia' de Herrera (Sevilla) 1890-1896”. En Homenaje a la profesora $M^{a}$ Dolores Tortosa Linde. Coordinado por P. Morales Rayar. Granada: Universidad, 2003.

Enríquez del Árbol, Eduardo. "Un espacio de paz y progreso: la logia femenina 'Hijas de la Regencia $n^{\circ} 124$ ' de Cádiz en el último tercio del siglo XIX”. En Discursos, realidades y utopías. La construcción del sujeto femenino en los siglos XIX y XX. Coordinado por Dolores Ramos y Teresa Vera. Barcelona: Anthropos, 2003.

Ferrer Benimeli, José Antonio. "Les femmes et la franc-maçonnerie espagnole au XIX siècle". En Les femmes et la Franc-maçonnerie. Des Lumières à nos jours, Tomo I, XVIII-XIX siècles. Coordinado por Cécile Révauger y Jacques Ch. Lemaire. Bruxelles: La Pensée et les Hommes, 2011.

Lacalzada, María José. "Du foyer à l'espace public. Les femmes et la Franc-maçonnerie en Espagne (1868-1936)". En Les Francs-maçons dans la cité. Coordinado por Luis Martin. Rennes: Presses Universitaires, 2000.

Lacalzada, María José. El cimiento mixto en masonería. El Derecho Humano en España 1893-1963. Madrid: Fundación Maria Deraismes, 2007.

Lacalzada, María José. "Hombres y mujeres en la masonería madrileña. Problemática y testimonios (1871-1917)". En La masonería en Madrid y en España del siglo XVIII al XXI. Coordinado por José Antonio Ferrer Benimeli. Zaragoza: Gobierno de Aragón, 2004.

Lacalzada, María José. "La intervención de la masonería en los inicios de la ciudadanía femenina". Género y ciudadanía. Revisiones desde el ámbito privado. Madrid: Universidad Autónoma, 1999.

Lacalzada, María José. “La mitad femenina 'para' la masonería y 'en' masonería. Balance y perspectivas". Investigaciones Históricas 23 (2003): 117-139.

Lacalzada, María José. "Laicismo, derechos humanos y derechos femeninos en la masonería". Arenal, Revista de Historia de las Mujeres, Laicismo, identidades y Cultura política II, no. 2 (julio-diciembre 2004): 5-26. 
Lacalzada, María José. "Mercedes de Vargas y Rosario de Acuña. El espacio privado, la presencia pública y la masonería (1883-1891)”. En Prototipos e imágenes de la mujer en los siglos XIX y XX. Coordinado Amparo Quiles Faz y Teresa Saurent Guerrero. Málaga: Atenea, 2002.

Lacalzada, María José. Mujeres en masonería. Antecedentes históricos entre las luces y las sombras (1868-1938). Premià de Mar: Clavell, Cultura, 2006.

López García, Paz, Antonio Morales Benítez y Fernando Sigler Silvera. "La mujer en la masonería gaditana. Estudios de las logias”. En La masonería española entre Europa y América. Coordinado José Antonio Ferrer Benimeli. Zaragoza: Gobierno de Aragón, 1995.

Marza, Suzanne. Premières manifestations de la Franc-maçonnerie féminine en Espagne au XIXe siècle. Aix-en-Provence : Septentrion, 1997.

Morales Ruiz, Juan José. "La mujer en la masonería menorquina del siglo XIX". En Masonería, revolución y reacción. Coordinado por José Antonio Ferrer Benimeli. Alicante: Instituto de Cultura 'Juan Gil-Albert', 1990.

Morte, Libertad. "La mujer y la masonería". Historia 16. Extra $n^{0} 4$ [La masonería] (noviembre 1977): 21-25.

Morte, Libertad. "La mujer y la masonería”. 1728 La masonería española 1939. Alicante: Instituto de Cultura 'Juan Gil-Albert', 1989.

Mosquera, María José. "Masonas devotas de lo esotérico". Marie Clair 16, no. 2 (noviembre 1987): 100-106.

Ortiz Albear, Natividad. "La logia 'Amor' de Madrid: una logia femenina en la II República”. En La masonería española en el 2000. Una revisión histórica. Coordinado por José Antonio Ferrer Benimeli. Zaragoza: Gobierno de Aragón, 2001.

Ortiz Albear, Natividad. Las mujeres en la masonería. Málaga: Atenea-Universidad, 2005.

Ortiz Albear, Natividad. Mujeres masonas en España. Diccionario biográfico (1868-1939). Santa Cruz de Tenerife: Ed. Idea, 2007.

Randouyer, Françoise. "Les Franc-maçonnes (1868-1898)". En Les espagnoles dans l'histoire. Une sociabilité démocratique (XIX-XX siècles). Coordinado por Danièle Bussy Genevois. Paris-Saint Denis: Presses Universitaires de Vincennes, 2002.

Randouyer, Françoise. "Presencia femenina precoz en las logias españolas (1868-1898)". En La masonería española en el 2000. Una revisión histórica. Coordinado por José Antonio Ferrer Benimeli. Zaragoza, Gobierno de Aragón, 2001.

Sánchez Ferré, Pere. "Els origins del feminisme a Catalunya 1870-1920". Revista de Catalunya 56 (octubre 1990): 33-49; L'Avenç 222 (febrero 1998): 8-13; no. 223 (marzo 1998): 6-11. 
Sánchez Ferré, Pere. "Mujer, feminismo y masonería en la Cataluña urbana de la Restauración”. En Masonería, política y sociedad. Coordinado por José Antonio Ferrer Benimeli. Zaragoza: CEHME, 1989.

Vigni, Francesca. "La masonería femenina italiana entre los siglos XIX y XX". En $L a$ masonería española entre Europa y América. Coordinado por José Antonio Ferrer Benimeli. Zaragoza: Gobierno de Aragón, 1995. 